\title{
Nonlinear rotordynamics of a drillstring in curved wells: models and numerical techniques
}

\author{
Khac-Long Nguyen ${ }^{\mathrm{b}}$, Quang-Thinh Tran ${ }^{\mathrm{a}}$, Marie-Ange Andrianoely ${ }^{\mathrm{a}}$, Lionel Manin ${ }^{\mathrm{a}}$, Sébastien Baguet ${ }^{\mathrm{a}}$, Régis \\ Dufour $^{\mathrm{a}}$, Mohamed Mahjoub ${ }^{\mathrm{b}}$, Stéphane Menand ${ }^{\mathrm{b}}$ \\ ${ }^{a}$ Univ. Lyon, INSA Lyon, CNRS UMR5259, LaMCoS, F-69621 France \\ ${ }^{b}$ DrillScan, Villeurbanne, F-69100, France
}

\begin{abstract}
The drilling operations for oil or geothermic extraction use a slender structure introduced inside the drill well, hanging from a derrick and driven by a rotary table at the surface. The drilling structure consists in a series of drillpipes and some heavy pipes at the well bottom. The drilling process involves nonlinear dynamic phenomena such as bit-bounce, stick-slip due to the well-drillstring multi-contacts and the pulsating mud flow. The drillstring vibrations may yield, the rate of penetration decrease, the premature wears and damages of drilling equipment. Many numerical models have been proposed to study the dynamics of drillstring to improve the reliability of drilling operations. However, the numerical models of drilling structures representing several kilometers length require a huge amount of computer memory storage and yield a too long computational time. The reduction technique proposed by Craig-Bampton (CB) has been developed for modelling the nonlinear dynamics of rotating machines to save the computational time but still limited in the context of rotordynamics. The paper focuses on the implementation of the CB method in the case of long drillstring assembly modelled by beam finite elements. The pre-loaded states of the drillstring due to the well curvature, well-structure contacts and fluid-structure interactions are determined and taken into account in the dynamic computation. The drillstring transient dynamics is simulated and the orbital motion of several nodes are analyzed. The result convergence and the reduction of computational time obtained by the CB method are investigated and discussed.
\end{abstract}

Keywords: Drillstring dynamics, transient response, reduction technique, rotor dynamics, fluid-structure interactions, contact

\section{Introduction}

The drilling structure for oil or geothermic extraction sketched in Figure 1a is a long drillstring mainly composed of the steel drill-pipes and a bottom-hole assembly (BHA). Drill-pipes are slender tubes of a 9-10 m length and screwed to each other by the tooljoints. The BHA includes the drill-collars, some stabilizers and one drill-bit. Such extra

Email address: khac-long.nguyen@drillscan.com (Khac-Long Nguyen) 
heavy pipes at the well bottom insure the required necessary Weight-On-Bit (WOB), they also permit controlling the structure dynamic behavior and the drilling direction (straight, directional or curved drilling). The drillstring assembly rotates in a well bore of several-kilometer length, its top part being protected with steel tube casings. The drilling fluid (or drilling mud) is a water-based or oil-based fluid, it circulates downward in the hollow drilling structure and then travels back upward to the surface in the well-drillstring annular space. This drilling mud is used to clear out the rock cuttings, to stabilize drillstring, to lubricate and to cool down the tool bit.

The drilling operations involve non linear dynamic phenomena [1] due to bit-rock interactions, structure-bore-hole contacts, stick-slip [2, 3,4 and fluid-structure interaction. Multiple vibration couplings between the axial, torsional and lateral motions may yield the dangerous damages of drilling structure $[5,6,7$. Improving the stability and the safety of the drilling process requires a thorough study of the drilling structure dynamics to avoid harmful vibrations.
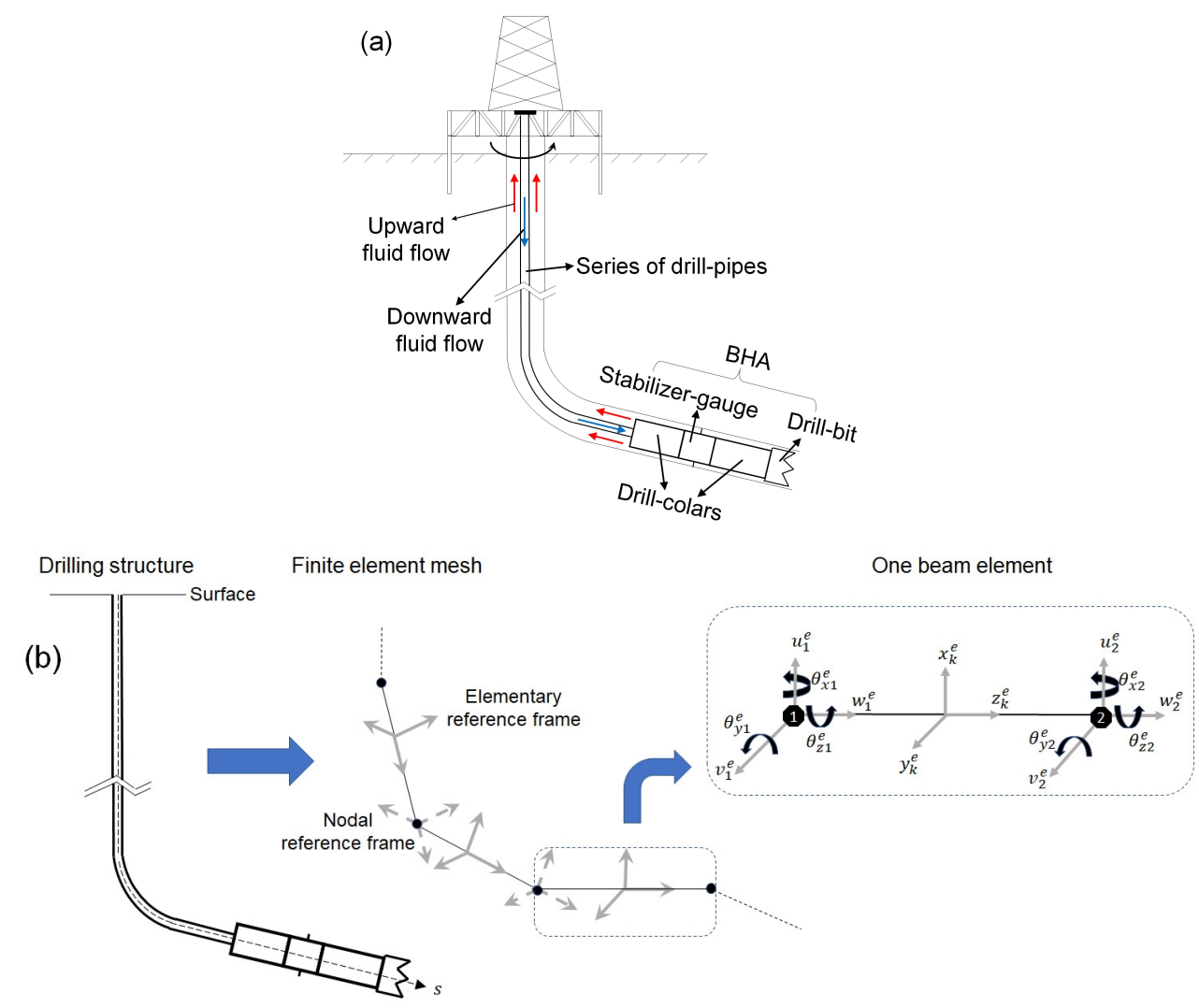

Figure 1: (a) Mechanical parts composing the drilling structure in the well bore. (b) Finite element mesh of drillstring along the curvilinear position $s$. The zoom represents the beam element $e$ with two nodes denoted 1 and 2 , and with the elementary reference frame $x_{k}^{e}, y_{k}^{e}, z_{k}^{e}$. Each node contains three translations $\left(u_{i}^{e}, v_{i}^{e}, w_{i}^{e}\right)$, two lateral rotations $\left(\theta_{x i}^{e}, \theta_{y i}^{e}\right)$ and one twist angle $\theta_{z i}^{e}$.

In order to control the vibrations of drilling structure, a first step is the determination of the natural frequencies. The axial vibrations can travel from the well bottom to the surface and have been studied with an analytical approach since a long time ago [8]. The torsional vibrations, usually associated with the stick-slip phenomena of bit-rock and 
with well-drillstring contacts, were investigated with some simple models such as the wave equation [9], a dynamics model with only torsional degrees of freedom (dof) [10,11] or the continuous system approach [12]. Lateral vibrations, also known as bending vibrations, are considered as the sources of drillstring and BHA failures and damages to the bore-hole wall. They have been studied since the mid 1960s and extensively investigated by the finite element method since 1990s [13, 14, 15] thanks to computer development. Recently, a beam element model with 6 dofs per node has been developed in [16] for computing the Campbell diagram of a drillstring immersed in fluid inside a curved well to determine the potential unstable speeds of rotation which may trigger dangerous vibrations and resonances.

In addition to the modal analysis which gives only a global view of structural dynamics, many numerical models have been developed for predicting the nonlinear dynamics in the time domain. Christoufou et al. [17] were focused on analyzing the axial and transverse vibrations of a rotating BHA. Ritto et al. [18] used the non-parametric approach to take into account the model uncertainties in the bit-rock interaction, the fluid-structure interaction and the impact forces. Tran et al. [19] extended this model to 3D curved wells, Liu [20], Gupta [21], Nandakumar [22], Yan [23] and their co-authors proposed the lumped parameter models with two dofs to study the axial-torsional vibration coupling for the vertical wells or drillstrings. Kreuzer et al. [24] have conducted an academic but representative experiment and analyzed the results by considering a simple model based on few dofs. Liao et al. [25] also developed a four-dof model to study the bending and torsional dynamics of drillstrings. The finite element method has been widely implemented for modeling the dynamic behavior of drillstring in horizontal wells [26, 27] and in curved wells [16, 28] by taking into account different well-structure and fluid-structure interaction models. Recently, Feng et al. have implemented a planar curved beam element in order to take into account 3D well profile and the drillstring-well interactions [29].

The numerical model of a long drillstring requires a great amount of dofs, large computer memory and long computational time. These difficulties can be overcomed by numerous methods of Component Mode Synthesis (CMS) introduced since a long time ago to reduce the dof number of finite element model [30, 31, 32, 33]. Among them is the Craig-Bampton (CB) technique [34]. It can be referred to the fixed interface model which combines the motions of connection dofs of the structure with the modes of the structure clamped at these connection dofs.

This paper applies the CB method for the finite element modelling of drilling structure in curved wells by using Timoshenko beams. Another novelty of this work is to consider the pre-loaded states of the drilling structure due to the well curvature and the static equilibrium in the dynamics computation. Section 2 presents the beam element formulation, the well-drillstring contact model and the fluid-structure interactions. The algorithm of dynamic computation is detailed in Section 3. This first step is the path computation which consists in calculating the internal loads of drillstrings due to the well curvature. The internal loads due to the path computation are considered for the second step, i.e. the static equilibrium computation to determine the contact points and the static pre-loaded state. The static position with the pre-loaded state obtained from the two first steps is considered as the initial position to begin the dynamic computation. Section 4 shows the reduced system obtained by the CB method. Section 5 considers a drilling structure in a helical well to illustrate each step. The convergence of CB results and the computational time versus the CB mode number are also analyzed. 


\section{Finite element model of nonlinear dynamics}

\subsection{Drillstring}

The beam element model of drillstring dynamics is presented in details in $[16,28]$. The drilling structure is meshed along the axial curvilinear direction using straight beam elements with two nodes per element. Each beam has a hollow circular cross section with inner and outer radii $R_{i}, R_{e}$. Six degrees of freedom (dofs) including three translations $(u, v, w)$, two lateral rotations $\left(\theta_{x}, \theta_{y}\right)$ and one twist angle $\theta_{z}$ are considered for each node. The 3D motion of one beam is characterized by its 12 nodal displacements:

$$
\mathbf{D}^{e}=\left[u_{1}^{e}, v_{1}^{e}, w_{1}^{e}, \theta_{x 1}^{e}, \theta_{y 1}^{e}, \theta_{z 1}^{e}, u_{2}^{e}, v_{2}^{e}, w_{2}^{e}, \theta_{x 2}^{e}, \theta_{y 2}^{e}, \theta_{z 2}^{e}\right]^{T},
$$

where [. $]^{T}$ is the transposed matrix, $u_{i}^{e}, v_{i}^{e}, w_{i}^{e}, \theta_{x i}^{e}, \theta_{y i}^{e}, \theta_{z i}^{e}$ with $i \in\{1,2\}$ denoting respectively six dofs of each node in the frame of reference of this beam (Figure 1b).

The dynamic energies of one beam are mainly related to the kinetic and strain energies. The finite element (FE) formula of elementary kinetic $E_{k a}^{e}$ and strain $E_{s a}^{e}$ energies are given by:

$$
E_{k a}^{e}=\frac{1}{2} \dot{\mathbf{D}}^{e T} \mathbf{M}_{a}^{e} \dot{\mathbf{D}}^{e}+\mathbf{D}^{e T}\left(\Omega \mathbf{C}_{a c}^{e}\right) \dot{\mathbf{D}}^{e}+\Omega \mathbf{F}_{\theta_{z}}^{e T} \dot{\mathbf{D}}^{e},
$$

and

$$
E_{s a}^{e}=\frac{1}{2} \mathbf{D}^{e T} \mathbf{K}_{a}^{e} \mathbf{D}^{e}
$$

where $\mathbf{M}_{a}^{e}, \mathbf{K}_{a}^{e}$ and $\mathbf{C}_{a c}^{e}$ are the elementary mass, stiffness and gyroscopic matrices. $\Omega \mathbf{F}_{\theta_{z}}^{e}$ is related to the moment due to the twist angle variation of two beam nodes with $\mathbf{F}_{\theta_{z}}^{e}=\left[0,0,0,0,0, \rho I_{d} l, 0,0,0,0,0, \rho I_{d} l\right]^{T}$ with $\rho$ the beam mass density, $l$ the element length, $I_{d}=\pi\left(R_{e}^{4}-R_{i}^{4}\right) / 4$ the area moment of inertia of beam cross-section about the neutral axis in bending direction. The Timoshenko beams are used by modifying elastic stiffness matrix terms with a coefficient $12 E I_{d} /\left(G_{s} S \beta l^{2}\right)$ to take into account the shear deformation, $E, G_{s}$ denoting the tensile and shear modulus, $S=\pi\left(R_{e}^{2}-R_{i}^{2}\right)$ being the cross-sectional area, $\beta$ being set to 0.9 .

The elementary parametric axial force $F_{a}^{e}$ and torque $T_{a}^{e}$ induce stress stiffening. $F_{a}^{e}$ yields a supplementary strain energy

$$
E_{G F}^{e}=\frac{F_{a}^{e}}{2} \int_{0}^{l}\left[\left(\frac{\partial u^{e}}{\partial z}\right)^{2}+\left(\frac{\partial v^{e}}{\partial z}\right)^{2}\right] d z
$$

whereas the non conservative axial torque $T_{a}^{e}$ gives the virtual work [14]:

$$
\delta \mathcal{T}_{G T}^{e}=T_{a}^{e} \int_{0}^{l}\left[\frac{\partial v^{e}}{\partial z} \delta\left(\frac{\partial^{2} u^{e}}{\partial z^{2}}\right)-\frac{\partial u^{e}}{\partial z} \delta\left(\frac{\partial^{2} v^{e}}{\partial z^{2}}\right)\right] d z
$$

The finite element expressions of Eqs. (4) and (5) lead to an elementary geometric stiffness matrix $\mathbf{K}_{g}^{e}$, which represents the axial-bending and torsion-bending couplings. 


\subsection{Well-drillstring contacts}

Due to the bending deflections, the occurring well drillstring contacts are modeled by a series of radial elastic stops create some shock and friction effects. In the reference frame of one node which is the same as the reference frame of the previous element (Figure 1b), the normal contact force is defined in the $x y$ plane (Figure 2) as:

$$
\vec{F}_{c n}=-\left(K_{c}(G) G+C_{c}(G) \dot{G}\right) \vec{n}
$$

with $\vec{n}=u / r \vec{x}+v / r \vec{y}, r=\sqrt{u^{2}+v^{2}}$ the radial displacement, $G=r-j_{0}$ the penetration of the beam cross-section in the well bore, $\dot{G}=(\dot{u} u+\dot{v} v) / r$ the penetration velocity and $j_{0}$ the radial clearance. The first term describes the elastic deformation and the second term represents the energy lost during the contact.

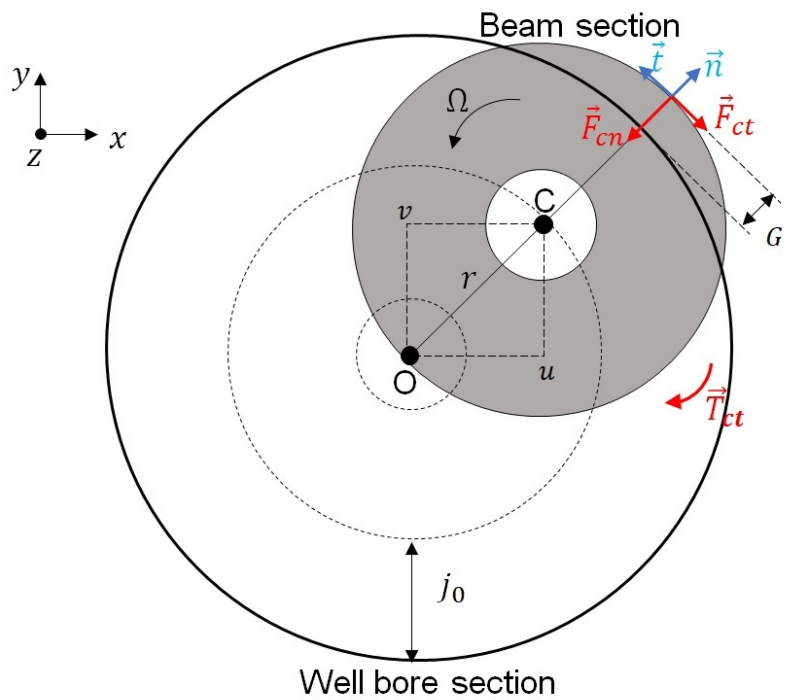

Figure 2: Contact between one beam cross-section of the drillstring and the well in the nodal reference frame $x y z$ with $z$ the axial direction, $\mathrm{O}$ and $\mathrm{C}$ the centers of well and of beam neutral lines, $u, v$ the two lateral translations, $r$ the radial displacement and $j_{0}$ the radial well-drillstring clearance. $G$ denotes the beam cross-section penetration in the well bore, which induces the normal contact force $\vec{F}_{c n}$ along the normal direction $\vec{n}$, the tangential friction force $\vec{F}_{c t}$ along the tangential direction $\vec{t}$ and the tangential friction torque $\vec{T}_{c t}$ along the $z$ axis.

Instead of the classical contact law which describes two discrete states (contact or no contact) at $G=0$ and may induce numerical instabilities, a contact law based on regularized stiffness and damping functions is applied as in [16]:

$$
K_{c}(G)=\frac{k_{c}}{2}\left[\frac{2}{\pi} \arctan \left(\pi \lambda_{k} G\right)+1\right], \quad C_{c}(G)=\frac{c_{c}}{2}\left[\frac{2}{\pi} \arctan \left(\pi \lambda_{c} G\right)+1\right],
$$

with $k_{c}$ and $c_{c}$ the nominal contact stiffness and damping. The arctan function and two parameters $\lambda_{k}, \lambda_{c}$ insure the continuity of these functions around $G=0$.

When the drillstring rotates and has lateral deflections (see Fig. 2), a well-drillstring contact also includes the tangential friction force and torque which both depend on the sliding velocity $v_{g}=(u \dot{v}-v \dot{u}) / r+\left(\Omega+\dot{\theta}_{z}\right) R_{e}[16]$. 
Using a smoothed Coulomb friction law, the tangential friction force and torque are given by:

$$
\vec{F}_{c t}=-\mu\left(v_{g}\right)\left(K_{c}(G) G+C_{c}(G) \dot{G}\right) \vec{t}, \vec{T}_{c t}=-\mu\left(v_{g}\right)\left(K_{c}(G) G+C_{c}(G) \dot{G}\right) R_{e} \vec{z},
$$

with $\vec{t}=-v / r \vec{x}+u / r \vec{y}$. The sign of the friction function $\mu\left(v_{g}\right)$ controls the friction force and torque direction. A regularized form of $\mu\left(v_{g}\right)$ is considered [16]:

$$
\mu\left(v_{g}\right)=\frac{v_{g}}{2 v_{r}}\left(\frac{1-\xi}{1+\frac{1-\xi}{2 v_{r} \mu_{d}}\left|v_{g}\right|}+\frac{1+\xi}{\left(1+\frac{1-\xi}{2 v_{r} \mu_{d}}\left|v_{g}\right|\right)^{2}}\right),
$$

with $\xi=\sqrt{1-\mu_{d} / \mu_{s}}, \mu_{d}$ and $\mu_{s}$ the dynamic and static friction coefficients, $v_{r}$ the regularized parameter.

\subsection{Fluid-drillstring interactions}

The effects of fluid in the annular space on the rotating drill pipes are described by different models. The first model developed in $[35,36,37,38]$ considered the annular fluid initially at rest and then entrained by the drillstring rotation, which yields the viscosity effect, the inertial and friction forces, whereas the fluid inside the hollow drillstring induces additional inertial force. The other model presented in [18] takes into account the effects of fluid flow in the axial direction on the drillstring. However, these models are limited to vertical wells. In this paper, the model in [18] is extended for the drillstring in a curved well.

The authors showed that the inviscid inner fluid flow induces some elastic forces in the axial and tangential directions of drillstring. The annular fluid is supposed to be viscous and then yields the friction forces due to the axial fluid flow and to the drillstring rotation. The inner and annular fluid effects on the drillstring depend on: the axial fluid flow $Q_{f}\left(\mathrm{~m}^{3} \cdot \mathrm{s}^{-1}\right)$, the fluid mass density $\rho_{f}\left(\mathrm{~kg} \cdot \mathrm{m}^{-3}\right)$, the viscosity damping coefficients: $C_{f}$ due to the axial flow and another one, implicitly included in the fluid model, due to the drillstring rotation, the curvilinear position of the well, the inner and annular pressures, the annular and inner cross-section areas.

The finite element formulation of the fluid elastic forces gives the elementary mass matrix $\mathbf{M}_{f i}^{e}$ for the inner fluid, and the elementary added mass, damping, stiffness matrices $\mathbf{M}_{f e}^{e}, \mathbf{C}_{f e}^{e}(\Omega), \mathbf{K}_{f e}^{e}$ and a static force $\mathbf{F}_{f e}^{e}$ for the annular fluid.

\section{Computational algorithm}

The computational algorithm consists in three steps sketched in Figure 3. The first step is the path computation of drillstring from its initial vertical position to its 3D curvilinear position on the well neutral line. External loads are not considered in this step. Stiffness matrices and internal reaction loads obtained from the path computation are then kept in the two following steps to take into account the pre-loaded state of the drillstring due to the well curvature. The second step concerns the computation of the drillstring static equilibrium position of the drillstring, subject to external loads, the nonlinear contacts with the well and the fluid-structure interaction. The axial and torsional deformations 

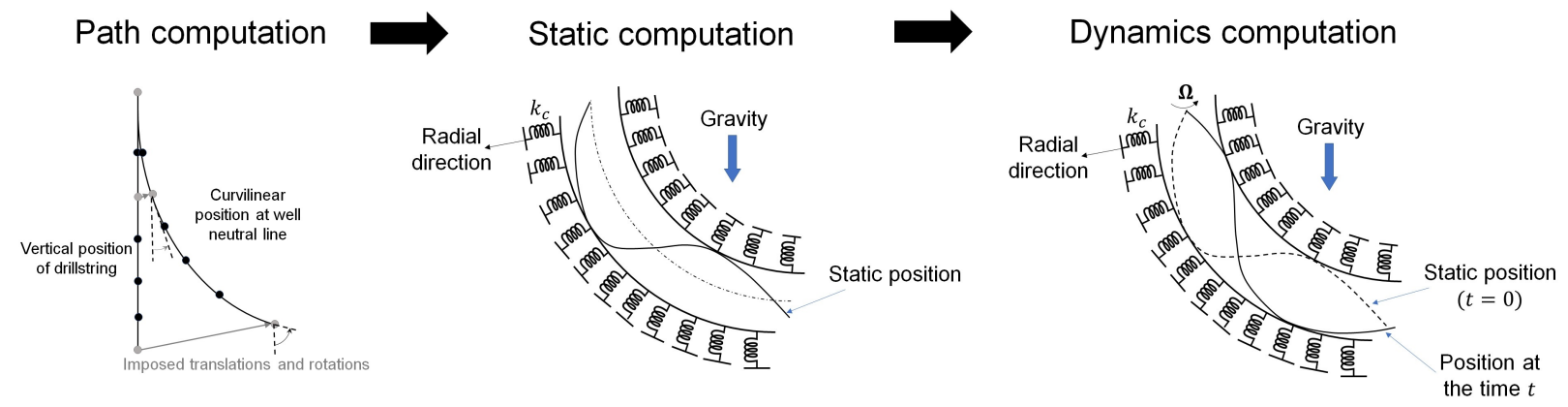

Figure 3: Sketch of the nonlinear dynamics computational algorithm. The first step is the path computation of drillstring from its initial vertical position to its final 3D curvilinear position on the well neutral line to determine the geometric stiffness matrix and the internal reaction loads due to the well curvature. Then the fluid and well-structure contact effects are added in the static equilibrium position and dynamics computations. The pre-loaded static state is considered as the initial position for the dynamics computation.

obtained from the static computation give the geometric stiffness matrices added to the structure stiffness matrix to take into account the pre-loaded static state of the drillstring. The static position is then considered as the initial position for the dynamics computation in the final step. The following subsections present each step in details.

\subsection{Path computation}

The aim of this section is to determine the stress stiffening characterized by the geometric stiffness matrix and internal reaction load of each beam element when the curved neutral line of the well is imposed as the target position of the drillstring. The path computation consists in imposing the translations and/or rotations of some drillstring nodes to move the drillstring from an initial straight vertical position to the well neutral line. The computational algorithm is based on an incremental method and the corotational formulation [39] due to the large displacements involved (see Figure 4a). The imposed translations and rotations are divided by $N$ increments.

The computation begins at the first increment $k=1$ from the vertical position $\mathcal{P}^{0}$. The drillstring position at the end of the $k^{\text {th }}$ increment is determined from the previous position by solving the following static equation:

$$
\left[\mathcal{K}_{a}+\mathcal{K}_{\text {gpa }}\left(\mathcal{D}^{k}\right)\right] \mathcal{D}^{k}=\mathcal{R}_{\text {int }}\left(\mathcal{D}^{k}\right)
$$

with $\mathcal{D}^{k}$ the displacement vector for the $k^{\text {th }}$ increment containing all drillstring dofs, $\mathcal{K}_{a}$ the stiffness matrix of the drillstring, $\mathcal{K}_{\text {gpa }}$ the geometric stiffness matrix calculated from the internal axial force and torque due to the beam element strain, $\mathcal{R}_{\text {int }}$ the internal reaction load vector due to the imposed translations and rotations. The total matrices and vectors in this section correspond to the dofs defined in the Cartesian frame of reference. They are obtained by assembling the elementary matrices and vectors defined in Section 2.1.

The position $\mathcal{P}^{k}$ of drillstring nodes at the $k^{\text {th }}$ increment is obtained by adding the displacement $\mathcal{D}^{k}$ to the previous position $\mathcal{P}^{k-1}$ :

$$
\mathcal{P}^{k}=\mathcal{P}^{k-1}+\mathcal{D}^{k} .
$$


The translation dofs are added terms by terms whereas the sum of rotations dofs is obtained by the corotational formulation using the quaternion product [39].

(a)

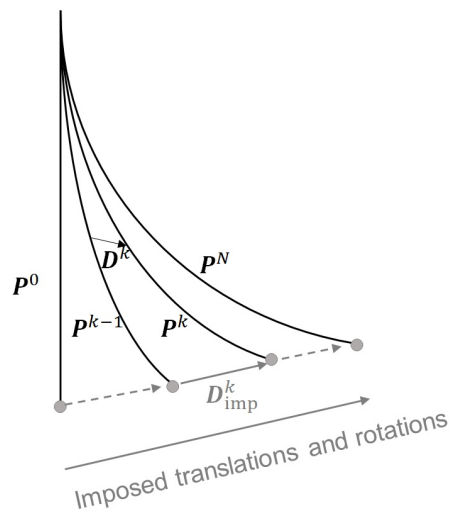

(b)

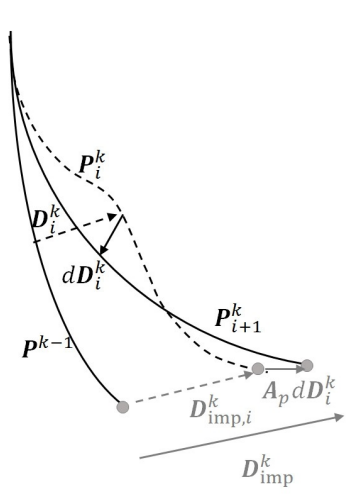

Figure 4: (a) Incremental algorithm of the path computation from the vertical position $\mathcal{P}^{0}$ to the final position $\mathcal{P}^{N}$ (the well neutral line). For the increment $k$, the displacement $\mathcal{D}_{\text {imp }}^{k}$ is imposed at some drillstring nodes to move the drillstring from the position $\mathcal{P}^{k-1}$ to the position $\mathcal{P}^{k}$. (b) Iterative algorithm for each increment $k$ to determine the position $\mathcal{P}^{k}$. For each iteration $i$, the imposed displacement $\mathcal{D}_{\text {imp, } i}^{k}$ and the solution $\mathcal{D}_{i}^{k}$ are corrected respectively by $\mathcal{A}_{p} d \mathcal{D}_{i}^{k}$ and $d \mathcal{D}_{i}^{k}$ determined by the Newton method. The position $\mathcal{P}_{i}^{k}$ is then updated by $\mathcal{P}_{i+1}^{k}$

The nonlinear equation (10) is solved by applying an iterative method with four steps (see Figure $4 \mathrm{~b}$ ):

- Initial solution $\mathcal{D}_{i=0}^{k}=\mathbf{0}$ and initial imposed displacement vector $\mathcal{D}_{\mathrm{imp}, i=0}^{k}=\mathcal{D}_{\mathrm{imp}}^{k}$

- Knowing the displacement vector $\mathcal{D}_{i}^{k}$ at the $i^{\text {th }}$ iteration, the correction is calculated by

$$
d \mathcal{D}_{i}^{k}=\left[\mathcal{K}_{a}+\mathcal{K}_{\text {gpa }}\left(\mathcal{D}_{i}^{k}\right)+\mathcal{K}_{p}\left(\mathcal{D}_{i}^{k}\right)\right]^{-1}\left[\mathcal{R}_{\text {int }}\left(\mathcal{D}_{i}^{k}\right)+\mathcal{R}_{p}\left(\mathcal{D}_{i}^{k}\right)\right]
$$

The penalization matrix $\mathcal{K}_{p}$ and vector $\mathcal{R}_{p}$ are applied in the previous equations to take into account the imposed translations and rotations:

$$
\mathcal{K}_{p}\left(\mathcal{D}_{i}^{k}\right)=10^{6} c_{p} \mathcal{A}_{p} \text { and } \mathcal{R}_{p}=10^{6} c_{p} \mathcal{A}_{p} \mathcal{D}_{\text {imp }, i}^{k}
$$

with $c_{p}$ the maximum absolute value of the terms of $\mathcal{K}_{a}+\mathcal{K}_{g p a}\left(\mathcal{D}_{i}^{k}\right), \mathcal{A}_{p}$ the diagonal matrix whose terms are set to 1 for the imposed dofs and to 0 for the others, $\mathcal{D}_{\mathrm{imp}, i}^{k}$ the displacement vector whose imposed dofs are set to the imposed translations and rotations at the $i^{\text {th }}$ iteration and the others are set to 0 . The large multiplier $10^{6}$ of $c_{p}$ is set for the penalization.

$\mathcal{K}_{\text {gpa }}$ and $\mathcal{R}_{\text {int }}$ are obtained by assembling the elementary geometric stiffness matrix $\mathcal{K}_{g p a}^{e}$ and reaction load $\mathcal{R}_{\text {int }}^{e}$. They depend on the strain vector $\mathcal{D}_{d, i}^{k, e}$ of each beam element, extracted from the nodal translations and rotations between two position $\mathcal{P}_{i}^{k}$ and $\mathcal{P}^{k-1}$ :

$$
\mathcal{D}_{d, i}^{k, e}=\left[0,0,0, \theta_{d, x 1}^{e}, \theta_{d, y 1}^{e}, \theta_{d, z 1}^{e}, 0,0, w_{d}^{e}, \theta_{d, x 2}^{e}, \theta_{d, y 2}^{e}, \theta_{d, z 2}^{e}\right]^{T}
$$


where $w_{d}^{e}$ denotes the elongation of each beam element along the element axis. The strain angles of two beam nodes $\left(\theta_{d, x}^{e}, \theta_{d, y}^{e}, \theta_{d, z}^{e}\right)$ are extracted from the rotation vector $\left(\theta_{x}, \theta_{y}, \theta_{z}\right)$ using the corotational formulation and the quaternion [39].

The elementary reaction load $\mathcal{R}_{\text {int }}^{e}$ is given by

$$
\mathcal{R}_{\text {int }}^{e}\left(\mathcal{D}_{i}^{k}\right)=-\left[\mathcal{K}_{a}^{e}+\mathcal{K}_{g p a}^{e}\left(\mathcal{D}_{i}^{k}\right)\right] \mathcal{D}_{d, i}^{k, e}
$$

$\mathcal{K}_{g p a}^{e}$ is characterized by the elementary internal axial force and torque, which at this iteration are defined by accumulating all element stretching from the previous iterations and increments:

$$
F_{a p a}^{e, k}=E S \frac{l^{e, k-1}-l^{e, 0}}{l^{e, 0}}+E S \frac{w_{d}^{e}}{l^{e, k-1}} \text { and } T_{a p a}^{e, k}=\sum_{j=1}^{k-1} \frac{2 I_{d} G_{s}}{l^{e, j-1}} \Delta \theta_{d}^{e, j}+\frac{2 I_{d} G_{s}}{l^{e, j-1}} \Delta \theta_{d, i}^{e, k},
$$

where $l^{e, j}$ the elementary length at the $j^{\text {th }}$ increment, $\Delta \theta_{d}^{e}$ the elementary torsional strain extracted from the difference of $\left(\theta_{d, x}^{e}, \theta_{d, y}^{e}, \theta_{d, z}^{e}\right)$ of two beam nodes in Eq. (14) by using the quaternion product [39].

- Applying the correction of solution:

$$
\mathcal{D}_{i+1}^{k}=\mathcal{D}_{i}^{k}+d \mathcal{D}_{i}^{k}
$$

It is observed that the penalization technique in Eqs. (12) and (13) yields the displacements of the imposed dofs after the first iteration which are close but not exactly equal to the imposed vector $\mathcal{D}_{\text {imp }}^{k}$. It should be corrected for the next iterations as:

$$
\mathcal{D}_{\text {imp }, i+1}^{k}=\mathcal{D}_{\text {imp }, i}^{k}+\mathcal{A}_{p} d \mathcal{D}_{i}^{k}
$$

- When the maximal absolute value of $d \mathcal{D}_{i}^{k}$ is smaller than a criterion $\varepsilon_{p a}$, the iterative loop stops and the position at the $k^{\text {th }}$ increment is obtained. Then the process is repeated for the $(k+1)^{\text {th }}$ increment starting from the drillstring position obtained at the $k^{\text {th }}$ increment.

\subsection{Static computation}

Following Section 2.2, the contact forces in the static and dynamics computations are defined in the nodal frame of reference. For computational convenience, the total matrices and vectors in the remaining sections of this paper are also defined in the nodal frame of reference instead of Cartesian one to avoid the repeated transformation of dofs between these two frames of reference in the contact force calculation.

The path computation gives the elementary geometric stiffness $\mathcal{K}_{g p a}^{e}$ and the total elementary reaction load $\mathcal{R}_{i p a}^{e}=$ $\sum_{j=1}^{N} \mathcal{R}_{\text {int }}^{e}\left(\mathcal{D}_{i}^{k}\right)$. Assembling these matrices and vectors in the nodal frame of reference yields the total geometric stiffness matrix $\mathbf{K}_{g p a}$ and internal load vector $\mathbf{R}_{i p a}$. They are considered in the static computation to take into account the pre-loaded state of the drillstring due to the well curvature. After the path computation, the fluid, the external 
loads are considered in the next computations and the modified stiffness matrix of drillstring immersed in fluid is $\mathbf{K}_{p a}=\mathbf{K}_{a}+\mathbf{K}_{g p a}+\mathbf{K}_{f e}$ where $\mathbf{K}_{a}$ is the total drillstring stiffness matrix and $\mathbf{K}_{f e}$ the total stiffness matrix due to the fluid-structure interaction.

The static equilibrium equation is given by:

$$
\left(\mathbf{K}_{p a}+\mathbf{K}_{g p o}(\mathbf{D})\right) \mathbf{D}=\mathbf{F}_{s}+\mathbf{F}_{c s}(\mathbf{D})+\mathbf{R}_{i p a}
$$

where $\mathbf{K}_{g p o}$ is the stress stiffening matrix depending on the axial and torsional deformations due to the static position. This matrix is obtained by assembling the elementary geometric stiffness matrices characterized by the elementary axial force $F_{a p o}^{e}$ and torque $T_{a p o}^{e}$ respectively:

$$
F_{\text {apo }}^{e}=\frac{E S}{l}\left(w_{2}^{e}-w_{1}^{e}\right) \text { and } T_{\text {apo }}^{e}=\frac{E I_{d}}{(1+v) l}\left(\theta_{z 2}^{e}-\theta_{z 1}^{e}\right) .
$$

with $v$ the Poisson ratio. The displacement vector $\mathbf{D}$ contains all the drillstring dofs in the nodal frame of reference. The FE vector $\mathbf{F}_{s}$ contains the external static loads such as gravity $g$, elastic fluid forces presented in Section 2.3, WOB and Torque-on-Bit (TOB), while $\mathbf{F}_{c s}$ the FE vector of contact forces and torques applied at the nodes of the drillstring. The static normal contact force at one node is defined from Eq. (6) by

$$
\vec{F}_{c n s}=-K_{c}(G) G \vec{n}
$$

All normal static contact forces are gathered in the FE vector $\mathbf{F}_{c n s}$.

Eq. (19) describes the real static position if only the normal contact forces are considered. When the structure rotates and has permanent contacts with the well, this situation corresponds to the quasi-static equilibrium. In this case, $\mathbf{F}_{c s}$ contains also the FE vector $\mathbf{F}_{c t s}$ of static tangential friction forces and torques applied to each contact node obtained from Section 2.2:

$$
\vec{F}_{c t s}=-\mu_{s} K_{c}(G) G \vec{t}, \vec{T}_{c t s}=-\mu_{s} K_{c}(G) G R_{e} \vec{z}
$$

The Newton-Raphson method is implemented to solve the nonlinear equation (19) with four steps:

- Initial displacement vector $\mathbf{D}_{1}$ is the solution of the static equation (19) but without the geometric stiffness matrix

$$
\mathbf{K}_{p a} \mathbf{D}=\mathbf{F}_{s}+\mathbf{F}_{c s}(\mathbf{D})+\mathbf{R}_{i p a} .
$$

The resolution of Eq. (23) briefly presented in [16] is depicted in details in Appendix A.

- Knowing the displacement vector $\mathbf{D}_{j}$ at the $j^{\text {th }}$ iteration, the correction is defined by

$$
d \mathbf{D}_{j}=-\left[\mathbf{K}_{p a}-\left.\frac{\partial \mathbf{F}_{c s}}{\partial \mathbf{D}}\right|_{\mathbf{D}=\mathbf{D}_{j}}+\left.\frac{\partial\left(\mathbf{K}_{g p o}(\mathbf{D}) \mathbf{D}\right)}{\partial \mathbf{D}}\right|_{\mathbf{D}=\mathbf{D}_{j}}\right]^{-1}\left[\left(\mathbf{K}_{p a}+\mathbf{K}_{g p o}\left(\mathbf{D}_{j}\right)\right) \mathbf{D}_{j}-\mathbf{F}_{s}-\mathbf{F}_{c s}\left(\mathbf{D}_{j}\right)-\mathbf{R}_{i p a}\right],
$$


where $\partial / \partial \mathbf{D}$ denotes the Jacobian matrix with respect to $\mathbf{D}$. Assuming that the initial displacement $\mathbf{D}_{1}$ is sufficiently close to the final solution of Eq. (19), the variation of $\mathbf{K}_{\text {gpo }}$ compared to $\mathbf{D}$ is negligible. The Jacobian matrix of geometric internal load $\mathbf{K}_{g p o}(\mathbf{D}) \mathbf{D}$ is then approximated by

$$
\left.\frac{\partial\left(\mathbf{K}_{g p o}(\mathbf{D}) \mathbf{D}\right)}{\partial \mathbf{D}}\right|_{\mathbf{D}=\mathbf{D}_{j}} \simeq \mathbf{K}_{g p o}\left(\mathbf{D}_{j}\right)
$$

- Applying the correction: $\mathbf{D}_{j+1}=\mathbf{D}_{j}+d \mathbf{D}_{j}$

- If the relative error $\frac{\left\|d \mathbf{D}_{j}\right\|_{2}}{\left\|\mathbf{D}_{j+1}\right\|_{2}}$ is smaller than a criterion $\varepsilon_{p o}$, the iterative loop is stopped. Otherwise, the process returns to step 2 .

This iterative algorithm converge to the FE vector $\mathbf{D}_{s}$.

\subsection{Dynamic response computation}

The nonlinear drillstring dynamic response is governed by the following set of equations:

$$
\mathbf{M} \ddot{\mathbf{D}}+\mathbf{C} \dot{\mathbf{D}}+\mathbf{K D}=\mathbf{F}(t, \mathbf{D}, \dot{\mathbf{D}}), \quad t \geq 0
$$

with

$$
\begin{aligned}
& \mathbf{M}=\mathbf{M}_{a}+\mathbf{M}_{f e}+\mathbf{M}_{f i}, \\
& \mathbf{C}=\Omega\left(\mathbf{C}_{a c}^{T}-\mathbf{C}_{a c}\right)+\mathbf{C}_{a d}+\mathbf{C}_{f e}(\Omega), \\
& \mathbf{K}=\mathbf{K}_{p a}+\mathbf{K}_{g p o}\left(\mathbf{D}_{s}\right)+\mathbf{C}_{a c}^{T} \dot{\Omega}, \\
& \mathbf{F}=\mathbf{F}_{s}+\mathbf{F}_{u}(t)+\mathbf{F}_{c}(\mathbf{D}, \dot{\mathbf{D}})-\mathbf{F}_{\theta_{z}} \dot{\Omega}+\mathbf{R}_{i p a} .
\end{aligned}
$$

$\mathbf{M}_{a}$ corresponds to the total mass matrix, $\mathbf{C}_{a c}$ represents the gyroscopic effect of the rotating drillstring and $\mathbf{F}_{\theta_{z}} \dot{\Omega}$ is related to the total torsional moment variation at the drillstring nodes, obtained by assembling the elementary matrices and vector presented in Section 2.1. $\mathbf{C}_{a d}$ is the Rayleigh damping matrix of the drillstring characterized by two Rayleigh coefficients $c_{M}$ and $c_{K}$ such as:

$$
\mathbf{C}_{a d}=c_{M} \mathbf{M}_{a}+c_{K}\left(\mathbf{K}_{a}+\mathbf{K}_{g p a}+\mathbf{K}_{g p o}\left(\mathbf{D}_{s}\right)\right)
$$

$\mathbf{M}_{f i}$ is the total mass matrix due to the inner fluid inertia and $\mathbf{M}_{f e}, \mathbf{C}_{f e}, \mathbf{K}_{f e}$ are the total added mass, damping and stiffness matrices related to the elastic forces of the annular fluid. They are given by assembling the fluid elementary matrices introduced in Section 2.3. $\mathbf{F}_{c}$ is the nodal dynamic contact load vector and $\mathbf{F}_{u}$ the vector of the nodal transient loads such as the mass unbalance forces.

The initial position is the static displacement $\mathbf{D}_{s}$ :

$$
\mathbf{D}(t=0)=\mathbf{D}_{s}, \quad \dot{\mathbf{D}}(t=0)=\mathbf{0} .
$$


The speed of rotation $\Omega(t)$ is imposed at the first node over the surface. The twist angle of the first node has the initial conditions:

$$
\theta_{z 1}(t)=\theta_{z 1}(0) \text { and } \dot{\theta}_{z 1}(t)=0, \quad \forall t \geq 0
$$

Since $\theta_{z 1}(0)$ is obtained by the static computation and usually considered as a blocked dof, then $\theta_{z 1}(0)=0$.

Eliminating the lines and columns of total matrices and vectors corresponding to the blocked dofs yields the following set of equations:

$$
\overline{\mathbf{M}} \ddot{\overline{\mathbf{D}}}+\overline{\mathbf{C}} \dot{\overline{\mathbf{D}}}+\overline{\mathbf{K}} \overline{\mathbf{D}}=\overline{\mathbf{F}}(t, \overline{\mathbf{D}}, \dot{\overline{\mathbf{D}}}), \quad t \geq 0
$$

\section{Craig-Bampton $(\mathrm{CB})$ method}

\subsection{Constraint and normal modes}

All dofs of the displacement vector are rearranged into two groups as

$$
\overline{\mathbf{D}}=\left[\begin{array}{l}
\overline{\mathbf{D}}_{C} \\
\overline{\mathbf{D}}_{I}
\end{array}\right],
$$

where $\overline{\mathbf{D}}_{C}$ includes the connection dofs on which external nodal loads and translation dofs of contact nodes obtained in Section 3.2 could be applied. The remaining dofs considered as the internal dofs are contained in $\overline{\mathbf{D}}_{I}$.

The Craig-Bampton modal basis includes the constrained modes and normal modes. Constrained modes are the deformations obtained by imposing a unit translation or rotation to one connection dof. Consequently, the number of constrained modes is equal to the number of connection dofs. The matrix $\boldsymbol{\Phi}_{C}$ of constrained modes is given by [34]

$$
\boldsymbol{\Phi}_{C}=\left[\begin{array}{c}
\mathbf{I}_{C C} \\
-\overline{\mathbf{K}}_{I I}^{-1} \overline{\mathbf{K}}_{I C}
\end{array}\right]=\left[\begin{array}{c}
\mathbf{I}_{C C} \\
\boldsymbol{\phi}_{C}
\end{array}\right] .
$$

The normal modes correspond to the vibration modes of internal dofs obtained by blocking all connection dofs. The number $\eta$ of first normal modes retained in the CB basis is the key parameter controlling the efficiency of CB method. The matrix of normal modes is given by

$$
\boldsymbol{\Phi}_{D}=\left[\begin{array}{c}
\mathbf{0}_{C D} \\
\boldsymbol{\Phi}_{I D}
\end{array}\right]
$$

where $D$ denotes a set of indices of the $\eta$ first normal modes. For a sake of simplicity, $\boldsymbol{\Phi}_{I D}$ is denoted by $\boldsymbol{\phi}_{D}$. Each column $\phi_{D j}$ of $\phi_{D}$ is the solution of the eigenvalue problem

$$
\omega_{j}^{2} \overline{\mathbf{M}}_{I I} \boldsymbol{\phi}_{D j}=\overline{\overline{\mathbf{K}}}_{I I} \boldsymbol{\phi}_{D j},
$$

with $\overline{\overline{\mathbf{K}}}=\left(\overline{\mathbf{K}}+\overline{\mathbf{K}}^{T}\right) / 2$. 
Assembling the matrices of the constrained and normal modes yields the reduction matrix $\boldsymbol{\Phi}=\left[\boldsymbol{\Phi}_{C} \boldsymbol{\Phi}_{D}\right]$. The physical displacement vector $\mathbf{D}$ is approximated by the reduced modal coordinate vector $\mathbf{q}$ as

$$
\overline{\mathbf{D}} \simeq \mathbf{\Phi q}, \quad \forall t \geq 0
$$

with

$$
\overline{\mathbf{D}}=\left[\begin{array}{l}
\overline{\mathbf{D}}_{C} \\
\overline{\mathbf{D}}_{I}
\end{array}\right], \quad \boldsymbol{\Phi}=\left[\begin{array}{cc}
\mathbf{I}_{C C} & \mathbf{0}_{C D} \\
\boldsymbol{\phi}_{C} & \boldsymbol{\phi}_{D}
\end{array}\right], \quad \mathbf{q}=\left[\begin{array}{c}
\mathbf{q}_{C} \\
\mathbf{q}_{D}
\end{array}\right]
$$

\subsection{Reduced dynamic equation}

First, the initial reduced vector $\mathbf{q}(0)$ should be determined. Equation (36) at $t=0$ is rewritten as

$$
\boldsymbol{\phi}_{C} \mathbf{q}_{C}(0)+\boldsymbol{\phi}_{D} \mathbf{q}_{D}(0)=\overline{\mathbf{D}}_{I}(0) \text { and } \mathbf{q}_{C}(0)=\overline{\mathbf{D}}_{C}(0)
$$

then, $\phi_{D} \mathbf{q}_{D}(0)=\overline{\mathbf{D}}_{I}(0)-\phi_{C} \overline{\mathbf{D}}_{C}(0)$.

Since only some first normal modes are retained, the matrix $\boldsymbol{\Phi}$ is rectangular. Consequently, knowing the initial displacement vector $\overline{\mathbf{D}}(0), \mathbf{q}(0)$ is then the solution of a minimization problem:

$$
\min \left\|\phi_{D} \mathbf{q}_{D}(0)-\overline{\mathbf{D}}_{I}(0)+\boldsymbol{\phi}_{C} \overline{\mathbf{D}}_{C}(0)\right\|_{2}^{2}
$$

Then,

$$
\mathbf{q}_{D}(0)=\left(\boldsymbol{\phi}_{D}^{T} \boldsymbol{\phi}_{D}\right)^{-1} \boldsymbol{\phi}_{D}^{T}\left[\overline{\mathbf{D}}_{I}(0)-\boldsymbol{\phi}_{C} \overline{\mathbf{D}}_{C}(0)\right]
$$

The same approach yields the reduced initial velocity:

$$
\dot{\mathbf{q}}_{D}(0)=\left(\boldsymbol{\phi}_{D}^{T} \boldsymbol{\phi}_{D}\right)^{-1} \boldsymbol{\phi}_{D}^{T}\left[\dot{\overline{\mathbf{D}}}_{I}(0)-\boldsymbol{\phi}_{C} \dot{\overline{\mathbf{D}}}_{C}(0)\right] .
$$

The initial condition in the reduced system is given by

$$
\mathbf{q}(0)=\left[\begin{array}{l}
\overline{\mathbf{D}}_{C}(0) \\
\left(\boldsymbol{\phi}_{D}^{T} \boldsymbol{\phi}_{D}\right)^{-1} \boldsymbol{\phi}_{D}^{T}\left[\overline{\mathbf{D}}_{I}(0)-\boldsymbol{\phi}_{C} \overline{\mathbf{D}}_{C}(0)\right]
\end{array}\right], \dot{\mathbf{q}}(0)=\left[\begin{array}{l}
\dot{\overline{\mathbf{D}}}_{C}(0) \\
\left(\boldsymbol{\phi}_{D}^{T} \boldsymbol{\phi}_{D}\right)^{-1} \boldsymbol{\phi}_{D}^{T}\left[\dot{\overline{\mathbf{D}}}_{I}(0)-\boldsymbol{\phi}_{C} \dot{\overline{\mathbf{D}}}_{C}(0)\right.
\end{array}\right] .
$$

The dynamic equation (31) is rewritten in the CB basis as

$$
\mathbf{m} \ddot{\mathbf{q}}+\mathbf{c} \dot{\mathbf{q}}+\mathbf{k q}=\mathbf{f}(t, \boldsymbol{\Phi q}, \boldsymbol{\Phi} \dot{\mathbf{q}}), \quad t \geq 0
$$

with $\mathbf{m}=\boldsymbol{\Phi}^{T} \mathbf{M} \boldsymbol{\Phi}, \mathbf{c}=\boldsymbol{\Phi}^{T} \mathbf{C} \boldsymbol{\Phi}, \mathbf{k}=\boldsymbol{\Phi}^{T} \mathbf{K} \boldsymbol{\Phi}$ and $\mathbf{f}=\boldsymbol{\Phi}^{T} \mathbf{F}$.

The Runge-Kutta time-integration scheme with an adaptive time step is applied to compute Eq. (43) with initial condition (42), it is presented in details in Appendix B. 


\section{Numerical application and discussions}

\subsection{Test case}

Figure 5 shows the helical geometry of a well defined by the following parametric Cartesian coordinates:

$$
\begin{aligned}
& X(s)=a \cos (s)-a, \\
& Y(s)=a \sin (s), \\
& Z(s)=b s,
\end{aligned}
$$

with $a=85.1 \mathrm{~m}, b=\sqrt{(L / \alpha)^{2}-a^{2}}, \alpha=\pi / 2, L=170.2 \mathrm{~m}$ the well length. The well circular cross section radius is $0.108 \mathrm{~m}$

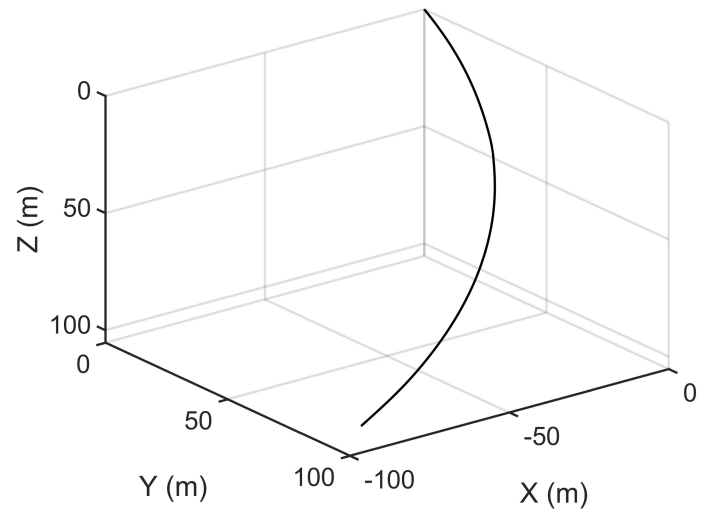

Figure 5: Well geometry in the Cartesian reference frame XYZ.

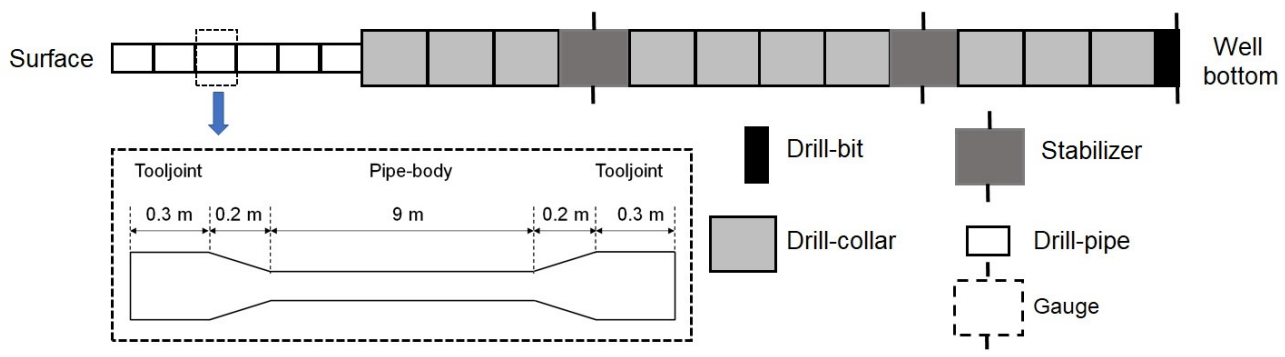

Figure 6: Mechanical parts composing the drillstring and geometry of a drill-pipe.

All components of the steel drilling structure of length $L$ are described by Figure 6: six drill-pipes begining from the surface, ten parts of drill-collars, two stabilizers and one drill-bit. One drill-pipe consists of two $0.3 \mathrm{~m}$ length tooljoints and of a $9 \mathrm{~m}$ length pipe-body. Three gauges are applied at the stabilizers and drill-bit with a very small well-gauge radial clearance to concentrate the drilling direction. The geometrical parameters of these components are listed in Table 1. The structural damping is characterized by two Rayleigh coefficients $c_{M}=0.03 \mathrm{~s}^{-1}$ and $c_{K}=0 \mathrm{~s}$ 
with the mass density $\rho=7900 \mathrm{~kg} \cdot \mathrm{m}^{-3}$, the Young modulus $E=2.0310^{11} \mathrm{~Pa}$ and the Poisson ratio $v=0.3$. The inner and annular fluids have a mass density $\rho_{f}=1200 \mathrm{~kg} . \mathrm{m}^{-3}$, a viscous damping coefficient $C_{f}=0.013$, a viscous coefficient $10^{-6} \mathrm{~m}^{2} \mathrm{~s}^{-1}$ and an axial flow $Q_{f}=0.01 \mathrm{~m}^{3} \cdot \mathrm{s}^{-1}$. It should be mentioned that the gravity is along $Z$ axis.

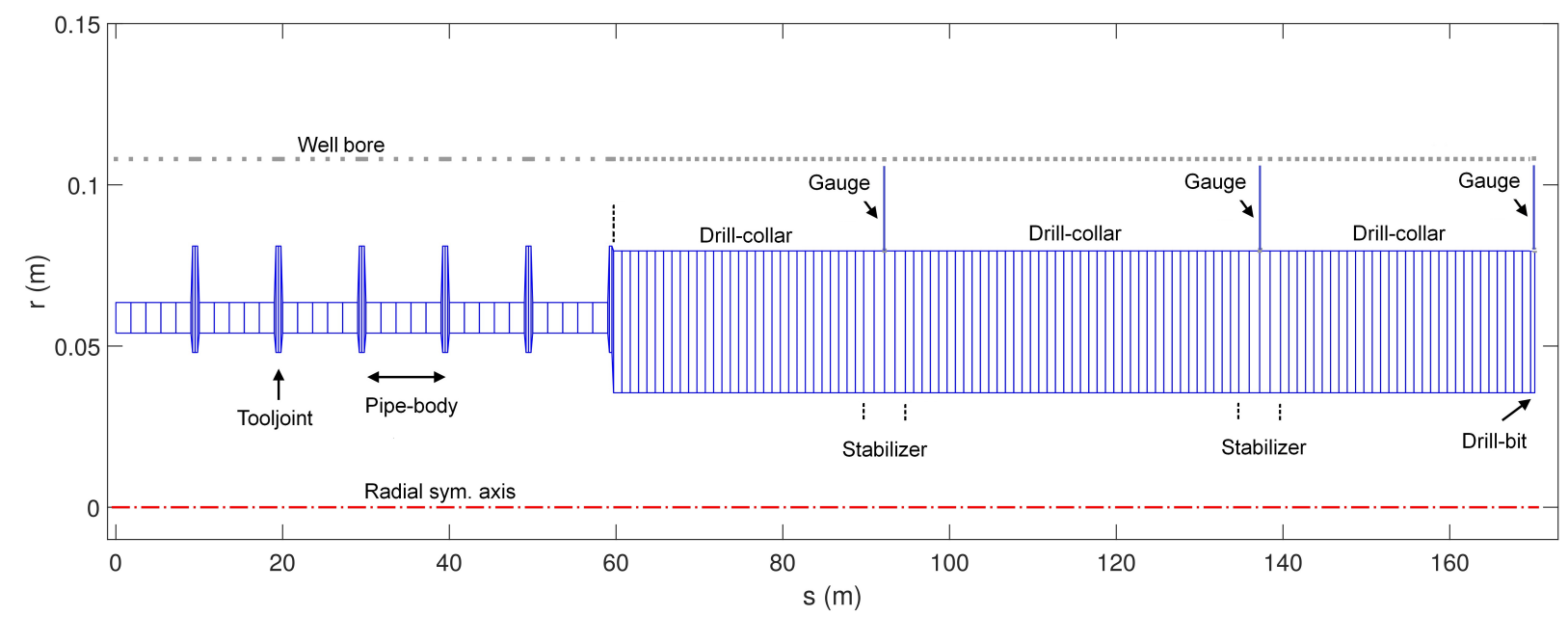

Figure 7: Finite element beam mesh of the drillstring inside the well bore, axisymetric representation of longitudinal section.

The drilling structure is meshed with 163 nodes and 162 beam elements. The meshes of the drillstring and its elementary parts are shown in Fig. 7. The beam element number of each drilling component is given in Table 1. The three translations of the first node over the surface and the lateral displacements of drill-bit node are blocked. The WOB and TOB are modeled by imposing a static force of $-10^{4} \mathrm{~N}$ and torque of -5000 N.m at the last node 163 .

The well-drillstring contacts are modeled by radial elastic stops. Their nominal contact stiffness $k_{c}$ and damping $c_{c}$ are $10^{7} \mathrm{~N} . \mathrm{m}^{-1}$ and $10^{4} \mathrm{~N} . \mathrm{s} . \mathrm{m}^{-1}$ respectively. Two regularized parameters $\lambda_{k}, \lambda_{c}$ are set to $710^{11} \mathrm{~m}^{-1}$. The dynamic and static contact friction coefficients are set respectively to $\mu_{d}=0.1$ and $\mu_{s}=0.2$. Table 2 gives the different clearances $j_{0}$ in the annular space due to different cross-sections of the drillstring.

\begin{tabular}{lccccc}
\hline Type & Length $(\mathrm{m})$ & Outer radii $(\mathrm{m})$ & Inner radii $(\mathrm{m})$ & Gauge radius $(\mathrm{m})$ & Beam numbers \\
\hline Pipe-body & 9 & 0.0635 & 0.054 & - & 5 \\
Tooljoint & 0.3 & 0.081 & 0.048 & - & 1 \\
Drill-collar part & 10 & 0.0795 & 0.0355 & - & 10 \\
Stabilizer & 5 & 0.0795 & 0.0355 & 0.108 & 4 \\
Drill-bit & 0.5 & 0.0795 & 0.0355 & 0.108 & 1 \\
\hline
\end{tabular}

Table 1: Geometric and mesh parameters of the drilling structure. 


\begin{tabular}{lc}
\hline Well - component & Clearance $j_{0}(\mathrm{~m})$ \\
\hline Well-pipe-body & 0.0445 \\
Well-tooljoint & 0.0270 \\
Well-stabilizer & 0.0285 \\
Well-gauge & 0 \\
Well-drill-collar & 0.0285 \\
Well-drill-collar & 0.0285 \\
Well-drill-bit & 0.0285 \\
\hline
\end{tabular}

Table 2: Different clearances for the drillstring components.

\subsection{Results of the path and static computation}

The path computation is carried out to move the drillstring from its initial vertical position to the well neutral line. Assuming that the variation of beam element lengths by the path computation is small, the final position of drillstring nodes can be estimated. The displacements in $X$ and $Y$ directions of nine nodes (dots in Figure 8a) are determined and imposed for the path computation with 10 increments. The positions of drilling structure at each increment are represented in Figure 8a. The comparison between Figures 8a and 5 shows that the final position of drillstring (gray line) is close to the helical well trajectory. Following Figure $8 \mathrm{~b}$, the path computation yields the total internal reaction forces of $\mathbf{R}_{i p a}$ which are the largest at some BHA and tooljoint nodes.

(a)

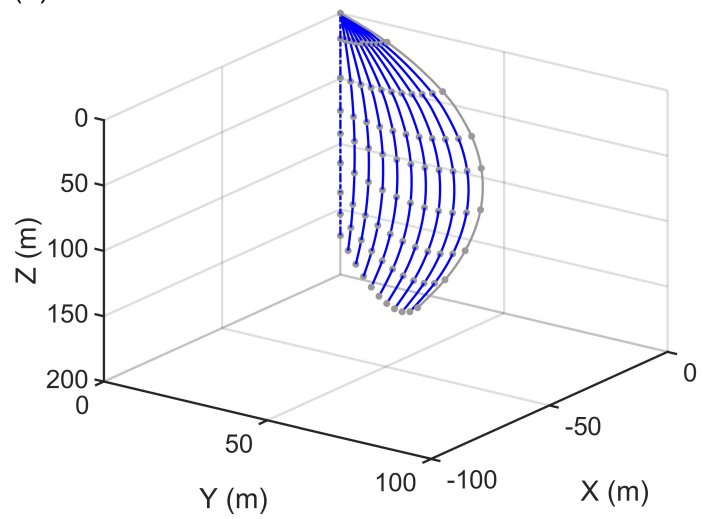

(b)

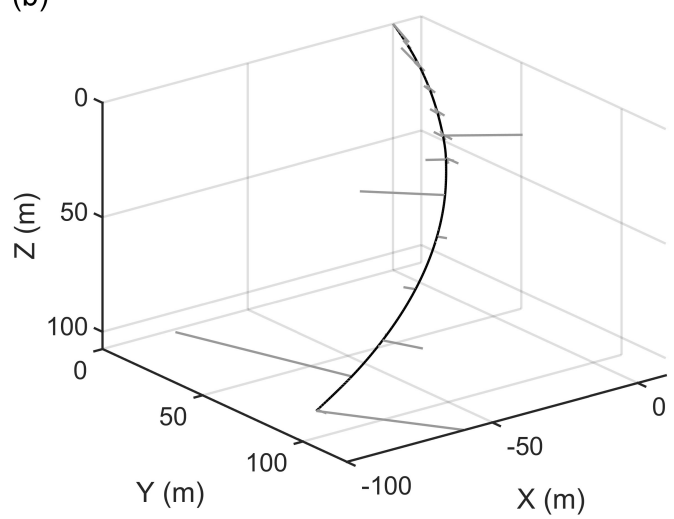

Figure 8: Path computation: (a) drillstring positions at each increment, the dots represent nine nodes whose displacements in $\mathrm{X}$, $\mathrm{Y}$ directions are imposed, (b) distribution of nodal internal reaction force (gray lines) in the Cartesian reference frame XYZ. 

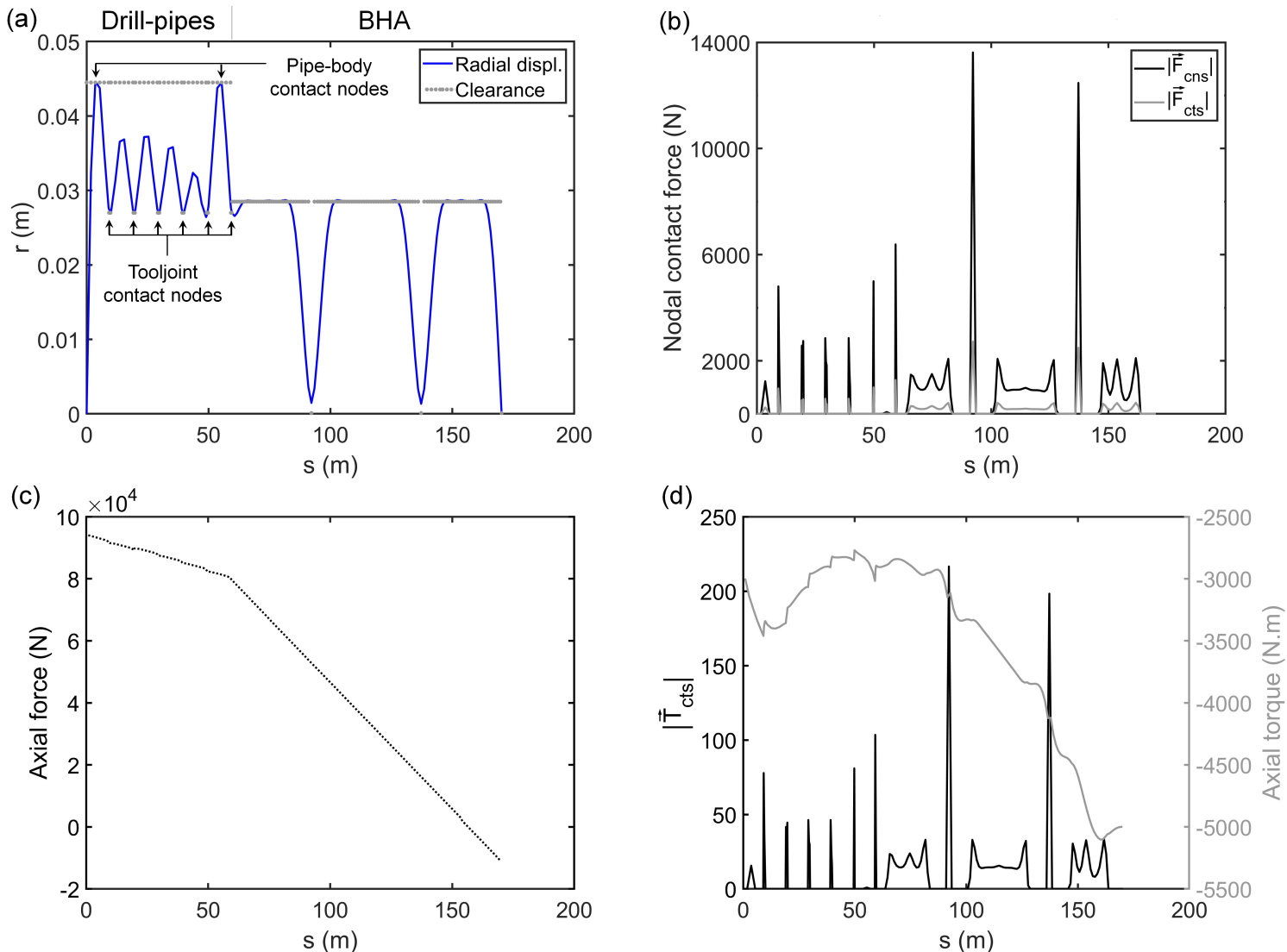

Figure 9: Quasi-static computation: (a) radial displacement $r$, (b) nodal normal $\left|\vec{F}_{c n s}\right|$ and tangential $\left|\vec{F}_{c t s}\right|$ contact forces, (c) elementary axial force, (d) elementary axial torque $\left|\vec{T}_{c t s}\right|$ (gray curve) and nodal axial friction torque versus the curvilinear position $s$.

The total internal reaction load and the elementary axial load obtained by the path computation are taken into account for the quasi-static equilibrium computation. Figures 9a and $9 \mathrm{~b}$ represent the radial displacement of each drillstring node versus the curvilinear coordinates and the distribution of contact forces and torques applied to the drilling structure in the helical well. There are 82 nodes in contact with the well. Many nodes of drill-collars and stabilizers of BHA contact the well due to their heavy weight. The well-drill-pipe contacts occur at the tooljoints and two pipe-bodies. Following Figure 9b, the contact loads are the largest at the gauge, tooljoint and some BHA nodes. The distribution of elementary axial force $F_{a p o}^{e}$ and torque $T_{a p o}^{e}$ is represented in Figure 9c. The last 15 elements of drilling structure are in compression state $\left(F_{\text {apo }}^{e}<0\right)$ due to the WOB and the remaining elements are in the tension state $\left(F_{a p o}^{e}>0\right)$ due to the structure heavy weight. $F_{a p o}^{e}$ and $T_{a p o}^{e}$ of the last element are close to the WOB and TOB applied to the drill-bit. Figure 9d shows that the multi-jumps of $T_{a p o}^{e}$ occur between two adjacent elements when the tooljoint nodes are in contact with the well. The line contact between the well and BHA induces the linear variation of $T_{a p o}^{e}$. 


\subsection{Results of the dynamics computation with the CB method}

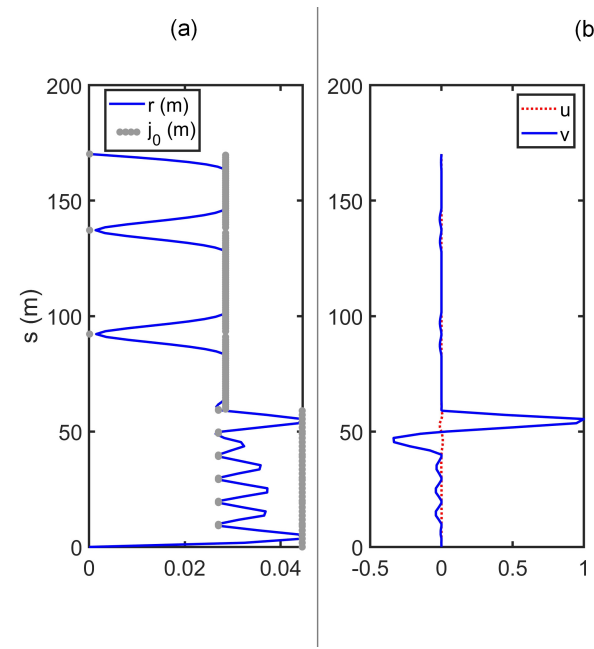

(b)

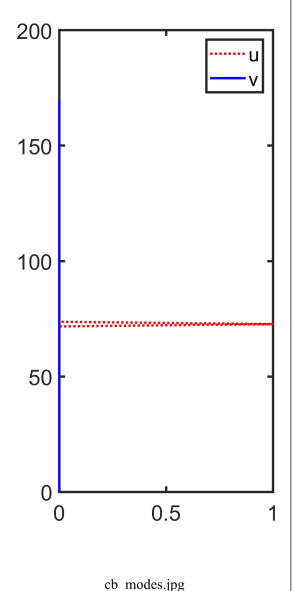

(c)

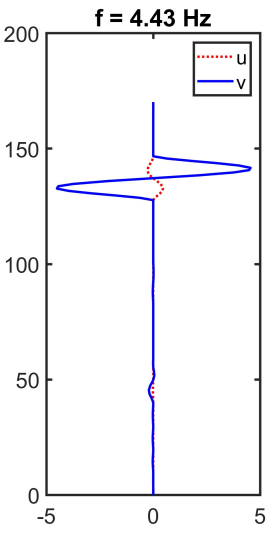

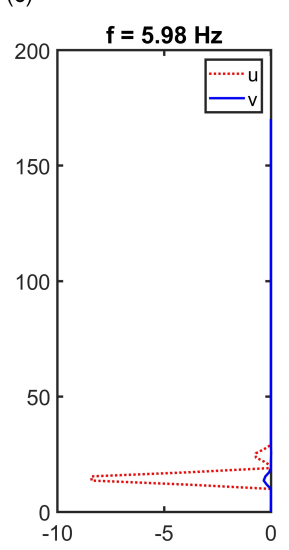

Figure 10: (a) Radial displacement $r$ of quasi-static computation and radial clearance $j_{0}$, lateral displacements $u$ and $v$ of (b) two constrained modes and of (c) two normal modes along the curvilinear position $s$.

The results obtained by the static computation are used to determine the CB modes. The number of constrained modes is 166, equal to the number of connection dofs including 2 dofs subjected to TOB, WOB and 164 lateral displacements of contact nodes obtain from the static position (see Section 4.1). Figure 10b represents two constrained modes of CB basis obtained by imposing the unit displacements $v$ and $u$ at the curvilinear position $s \simeq 55.4 \mathrm{~m}$ and $s \simeq 72.7 \mathrm{~m}$ respectively. These positions correspond to the static contact nodes of tooljoints and BHA whose lateral displacements are considered as the connection dofs (see Figure 10a). Two normal modes and their natural frequencies are represented in Figure 10c. Following Figures 10a and 10c, the lateral displacements of normal modes are obtained by blocking the connection dofs including the lateral displacements of static contact nodes.

The dynamics of the drilling structure in the helical well is computed from $t=0 \mathrm{~s}$ to $t=20 \mathrm{~s}$. An exponential time law $\Omega(t)=120-120 e^{-6 t}(\mathrm{rpm})$ is imposed for the speed of rotation at the first node over the surface. No transition WOB and TOB are considered. Table 3 compares the computational time obtained with the total and reduced systems versus different numbers $\eta$ of normal modes. Compared to the computation with the full system, the CB method with $\eta \leq 180$ reduces the computational time from 10 to 2.5 times. When $\eta$ increases more than 220, the computational time of CB system grows strongly and is larger than the one with the full system. The quick increase of computational time versus $\eta$ is mainly due to the conversion at each time step between the CB dofs and internal physical dofs to compute the nonlinear contact forces (see Eq. (43)). Under the assumption where the internal dofs are always free of contact with the well, this conversion can be avoided, and then the computational time can be much more reduced. 


\begin{tabular}{|c|c|c|c|c|c|}
\hline Normal mode number $\eta$ & 0 & 60 & 180 & 220 & 300 \\
\hline Constraint mode number & 166 & 166 & 166 & 166 & 166 \\
\hline Reduced dof number & 166 & 226 & 302 & 386 & 466 \\
\hline Computational time (s) & 147.99 & 155.97 & 461.83 & 1553.48 & 4475.19 \\
\hline Full system time/CB time & 9.44 & 8.95 & 3.02 & 0.89 & 0.31 \\
\hline
\end{tabular}

Table 3: Computation time of drillstring dynamics obtained with the CB method for different numbers of normal modes. The total free physical dof number is 972 and the computational time with the full system is $1396.49 \mathrm{~s}$.

The convergence of $\mathrm{CB}$ results versus the normal mode number is analyzed by defining two criteria:

$$
\epsilon_{t}(t)=\frac{1}{3}\left[\frac{\sqrt{\sum_{n}\left(u_{c b}\left(s_{n}, t\right)-u_{r e f}\left(s_{n}, t\right)\right)^{2}}}{\sqrt{\sum_{n} u_{r e f}^{2}\left(s_{n}, t\right)}}+\frac{\sqrt{\sum_{n}\left(v_{c b}\left(s_{n}, t\right)-v_{r e f}\left(s_{n}, t\right)\right)^{2}}}{\sqrt{\sum_{n} v_{r e f}^{2}\left(s_{n}, t\right)}}+\frac{\sqrt{\sum_{n}\left(w_{c b}\left(s_{n}, t\right)-w_{r e f}\left(s_{n}, t\right)\right)^{2}}}{\sqrt{\sum_{n} w_{r e f}^{2}\left(s_{n}, t\right)}}\right]
$$

and

$$
\epsilon_{n}(s)=\frac{1}{3}\left[\frac{\sqrt{\sum_{i}\left(u_{c b}\left(s, t_{i}\right)-u_{r e f}\left(s, t_{i}\right)\right)^{2}}}{\sqrt{\sum_{i} u_{r e f}^{2}\left(s, t_{i}\right)}}+\frac{\sqrt{\sum_{i}\left(v_{c b}\left(s, t_{i}\right)-v_{r e f}\left(s, t_{i}\right)\right)^{2}}}{\sqrt{\sum_{i} v_{r e f}^{2}\left(t_{i}\right)}}+\frac{\sqrt{\sum_{i}\left(w_{c b}\left(s, t_{i}\right)-w_{r e f}\left(s, t_{i}\right)\right)^{2}}}{\sqrt{\sum_{i} w_{r e f}^{2}\left(s, t_{i}\right)}}\right],
$$

where $\left(u_{c b}, v_{c b}, w_{c b}\right)$, and $\left(u_{r e f}, v_{r e f}, w_{r e f}\right)$ denote three translations obtained by the reduced and the full models respectively. The first criterion $\epsilon_{t}$ represents the relative error of the three translations of all 163 drillstring nodes with the curvilinear positions $s_{n, n=1 \ldots 163}$ at each time iteration $t$ while the second one the relative error of the three displacements of one node at the curvilinear position $s$ in the time period [0 s, $20 \mathrm{~s}]$.
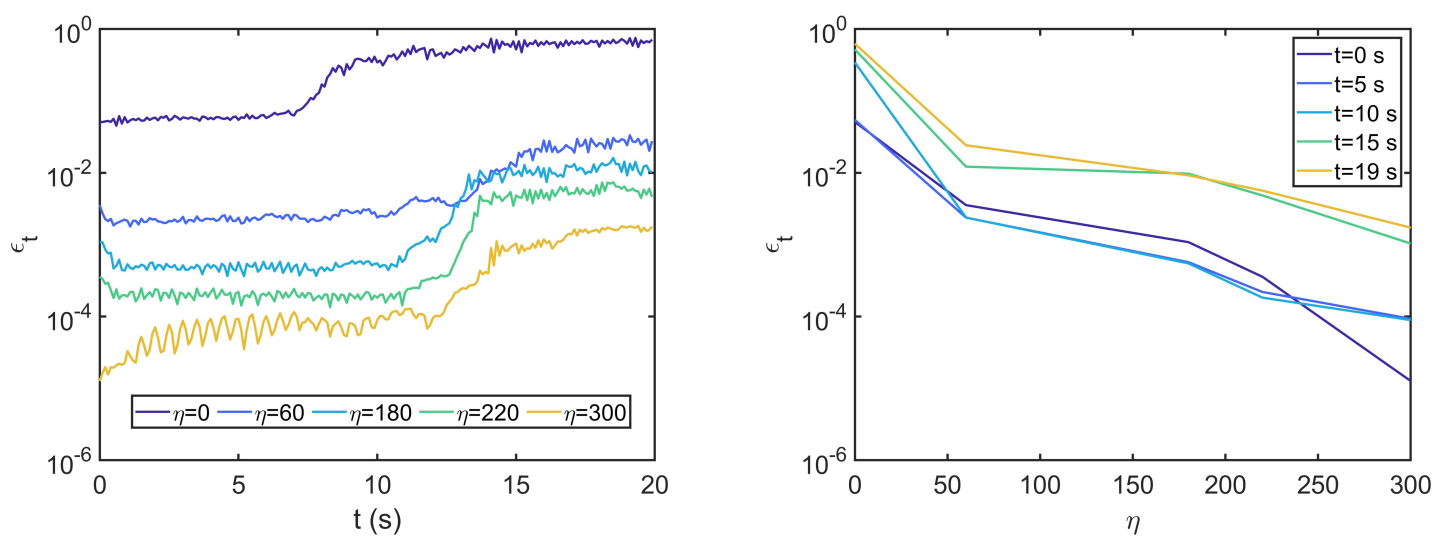

Figure 11: (a) First convergence criterion $\epsilon_{t}$ for different normal mode numbers $\eta$ versus the time $t$ and (b) $\epsilon_{t}$ for different time iterations versus the normal mode number. 

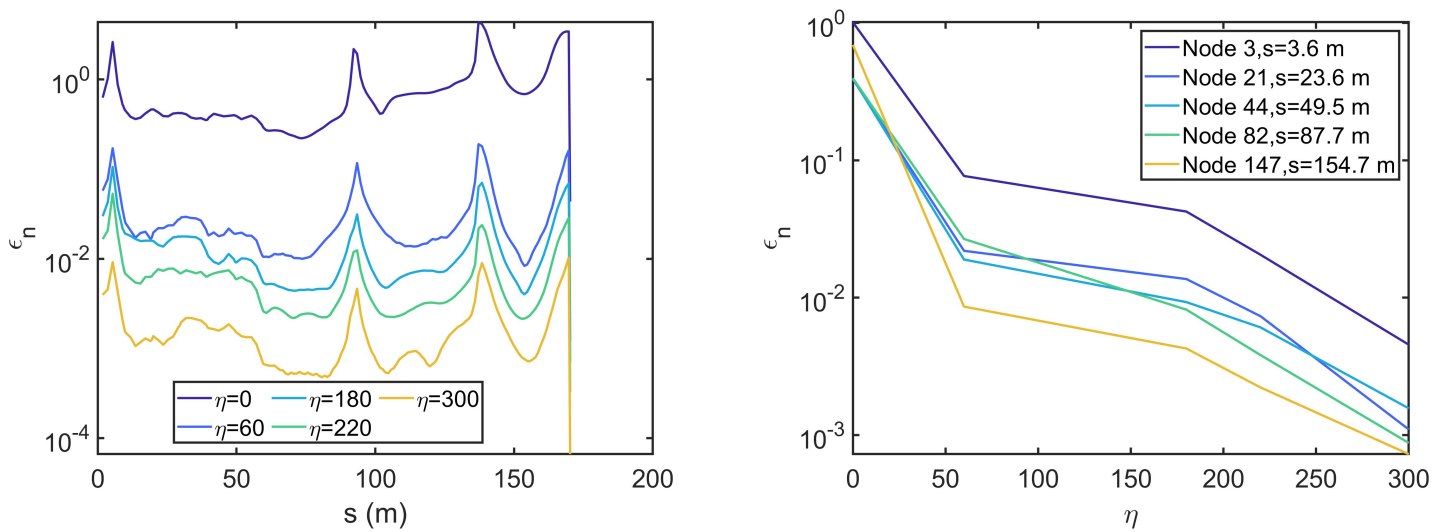

Figure 12: (a) Second convergence criterion $\epsilon_{n}$ for different normal mode numbers $\eta$ versus the curvilinear position $s$ and (b) $\epsilon_{n}$ for different curvilinear positions versus the normal mode number.

Figure 11 shows that the criterion $\epsilon_{t}$ increases with $\eta$. For each $\eta, \epsilon_{t}$ increases versus the time. This phenomenon is due to the fact that the approximation of initial position of drillstring nodes by the CB method induces a small error $\epsilon_{t}$ at $t=0 \mathrm{~s}$ even with a large number of normal modes and this error is accumulated due to the time computation. Figure 12 shows the second convergence criterion $\epsilon_{n}$ which decreases for large $\eta$. For each $\eta, \epsilon_{n}$ is the largest for the pipe-body node 3 and two gauge nodes 86 and 130.

Criteria $\epsilon_{t}, \epsilon_{n}$ only represent the global convergence of the $\mathrm{CB}$ method, a more detailed comparison between the results obtained by the $\mathrm{CB}$ method and by the full system should be carried out for some nodes of the drilling structure. Figures 13a-e compare the radial displacements of pipe-body (Nodes 3 and 21), tooljoint-BHA interface (Node 44), BHA (Nodes 82 and 147), obtained by the CB method with $\eta=180$ and by the full system. This comparison shows that the CB method yields the same global dynamic behavior as the full system. Since the results obtained by the CB method $\eta=180$ give a good convergence with $\epsilon_{t}, \epsilon_{n} \leq 10 \%$ with a smaller computational time compared to the reference results (see Figs. 11, 12 and Tab. 3), they are considered for the vibration analysis. According to the results plotted in Figs. 13a-e, Node 147 is always in contact and Node 44 shows intermittent contacts with the well at contrary to the nodes 21 and 82 free of contact. The contact model described in Sec. 2.2 allows a small penetration of drillstring in the well (see Figs. 13a, c, e). Figure $13 \mathrm{f}$ represents the radial acceleration $a_{x y}=\sqrt{\ddot{u}^{2}+\ddot{v}^{2}}$ versus the time and the curvilinear positions. The drillstring vibration becomes more remarkable when $t \geq 10 \mathrm{~s}$ due to the amplified variation of the radial displacements as shown in Figs. 13a-e. The first $50 \mathrm{~m}$ part corresponding to 6 drill-pipes shows a larger lateral vibration than the heavy BHA.

The variation $\Omega+\dot{\theta}_{z}$ of the axial rotation angle of aforementioned nodes, the surface and drill-bit nodes are analyzed by Figure 14a. Their axial rotation angles oscillate around the speed of rotation $\Omega$ imposed at the surface node. This oscillation grows slowly until $10 \mathrm{~s}$ and then increases strongly to attain a stable variation level after $15 \mathrm{~s}$. Node 3 having an intermittent contact and strong lateral vibration has the smallest variation of axial rotation angle. The most important variation of $\Omega+\dot{\theta}_{z}$ can be observed for the non-contact pipe-body (Node 21), BHA (Node 147) and drill-bit 
(Node 163). Following Figure 14b, after $10 \mathrm{~s}$, the drill-bit axial rotation angle oscillates from $-45 \mathrm{rpm}$ to $289 \mathrm{rpm}$. The large range of variation and the negative values are due to all friction torques of multi-contacts between the drillstring and the well.
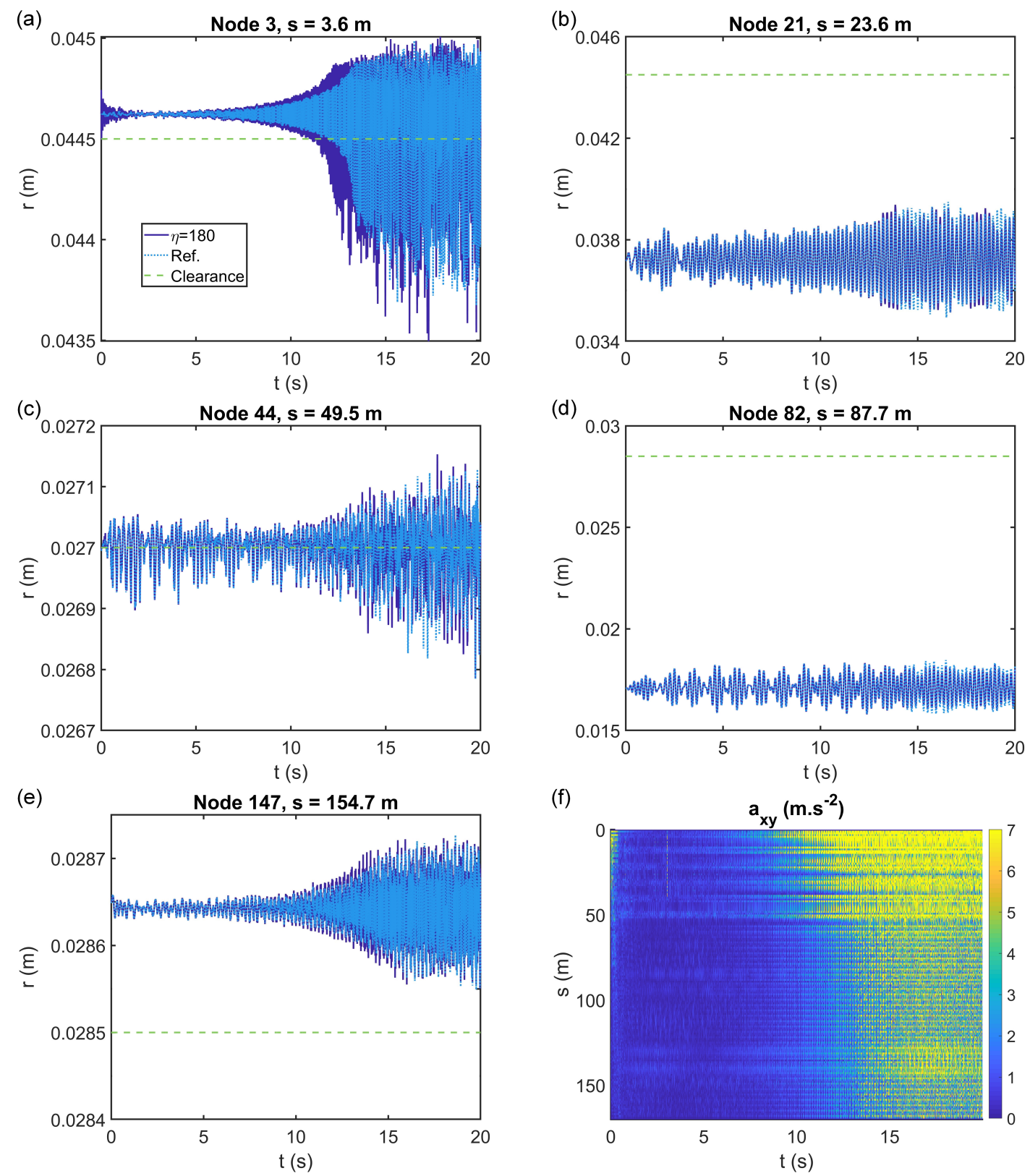

Figure 13: (a-e) Radial displacements of some nodes at different curvilinear positions $s$, obtained by the CB method with 180 normal modes compared to the results of the computation with the full system, (f) radial acceleration versus the time and curvilinear position obtained by the $\mathrm{CB}$ method with 180 normal modes. 

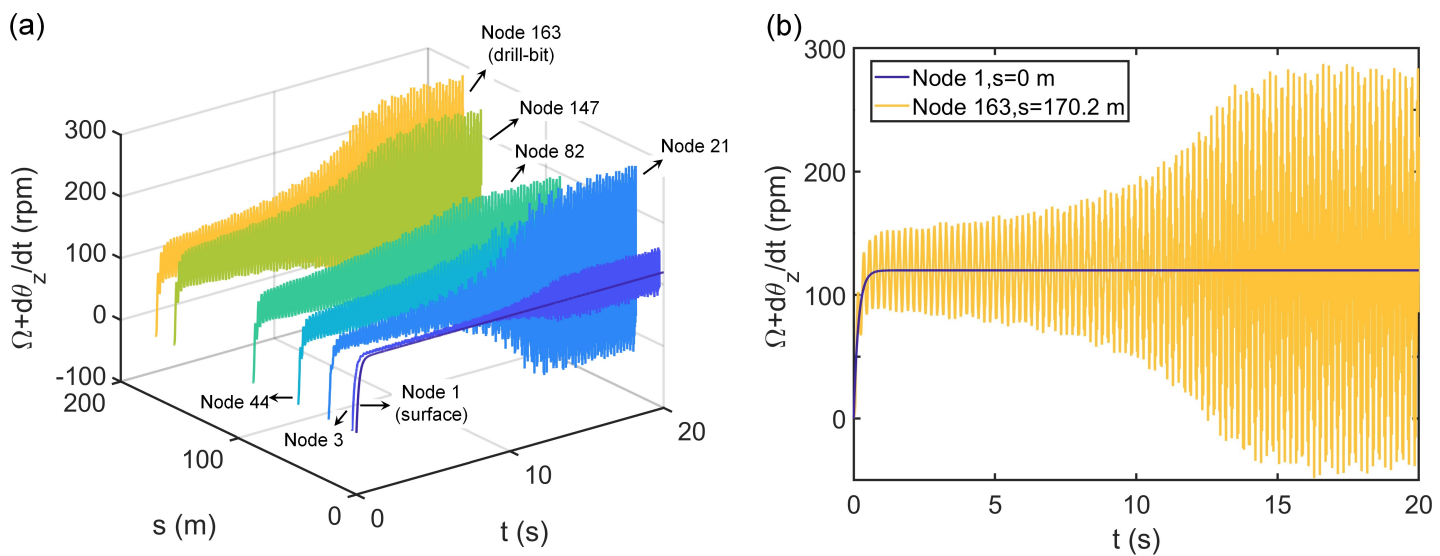

Figure 14: Torsional angle velocity of drillstring nodes $1(s=0 \mathrm{~m}), 3(s=3.6 \mathrm{~m}), 21(s=23.6 \mathrm{~m}), 44(s=49.5 \mathrm{~m}), 82(s=87.7 \mathrm{~m}), 147$ $(s=154.7 \mathrm{~m})$ and $163(s=170.2 \mathrm{~m})$ obtained by the CB method with 180 normal modes, $s$ being the curvilinear position.

\section{Conclusion}

The prediction of the static and transient dynamic behavior of a drillstring in a 3D well has been simulated by using a Finite Element model either full or reduced with the Craig-Bampton technique. These models take into account the pre-loaded state of drillstring due to the well curvature, the well-drillstring contacts, the fluid-structure interactions and all external static loads such as the WOB, TOB and the gravity force.

The numerical convergence of the CB method is analyzed for a drillstring in the helical well. A variable law of speed of rotation is imposed at the first drillstring node at the surface. The results obtained by the CB method converge to those computed with the full system by increasing the number of normal modes. However, increasing the number of normal modes of the $\mathrm{CB}$ basis induces a longer computational time due to the conversion at each time step between the $\mathrm{CB}$ and physical dofs to compute the contact forces. The $\mathrm{CB}$ method reduces the computational time about three times with a relative error about $5 \%$. One difficulty of the $\mathrm{CB}$ method for the time computation is that the relative error is accumulated at each time step.

For this test case, the drill-pipes show the stronger lateral vibrations than the BHA because the BHA has a larger weight and more contacts with the well than the drill-pipes. Some drillstring nodes have intermittent or permanent contacts with the wells. The axial rotation angles of some drillstring nodes, especially the drill-bit node, show the significant variations around the speed of rotation imposed at the surface node and can have negative values. These phenomena are due to all friction torques of many contacts between the drillstring and the well.

\section{Acknowledgment}

The authors are indebted to the Agence Nationale de la Recherche (ANR) for its financial support given to this research. In the framework of the LaBCoM-SME program of ANR 15-LCV4-0010-01, this research is conducted by DrilLab, a joint laboratory founded by the cooperation of DrillScan and INSA Lyon - LaMCoS. 


\section{Appendix A. Static computation without the geometric stiffness matrix}

The static equation without the geometric stiffness matrix is given by

$$
\mathbf{K}_{p a} \mathbf{D}=\mathbf{F}_{s}+\mathbf{F}_{c s}(\mathbf{D})+\mathbf{R}_{i p a}
$$

The Newton-Raphson method is implemented to solve this equation by an iterative loop with four steps:

- Initial displacement vector $\mathbf{D}_{0}$ is chosen as $\mathbf{K}_{p a}^{-1} \mathbf{F}_{s}$.

- The displacement vector $\mathbf{D}_{i}$ at the $i^{\text {th }}$ iteration is assumed to be known, the increment correction is defined by :

$$
d \mathbf{D}_{i}=-\left(\mathbf{K}_{p a}-\left.\frac{\partial \mathbf{F}_{c s}}{\partial \mathbf{D}}\right|_{\mathbf{D}=\mathbf{D}_{i}}\right)^{-1}\left(\mathbf{K}_{p a} \mathbf{D}_{i}-\mathbf{F}_{s}-\mathbf{F}_{c s}\left(\mathbf{D}_{i}\right)-\mathbf{R}_{i p a}\right)
$$

where $\frac{\partial \mathbf{F}_{c s}}{\partial \mathbf{D}}$ is the Jacobian matrix of $\mathbf{F}_{c s}$ with respect to $\mathbf{D}$ :

$$
\frac{\partial \mathbf{F}_{c s}}{\partial \mathbf{D}}=\left(\begin{array}{ccccc}
\mathbf{J}_{1} & \mathbf{0} & \ldots & \mathbf{0} & \mathbf{0} \\
\mathbf{0} & \mathbf{J}_{2} & \ldots & \mathbf{0} & \mathbf{0} \\
\vdots & \vdots & \ddots & \vdots & \vdots \\
\mathbf{0} & \mathbf{0} & \ldots & \mathbf{J}_{P-1} & \mathbf{0} \\
\mathbf{0} & \mathbf{0} & \ldots & \mathbf{0} & \mathbf{J}_{P}
\end{array}\right),
$$

$P$ is the node number. $\mathbf{J}_{p, p=1 \ldots P}$ is the nodal Jacobian matrix:

$$
\mathbf{J}_{p}=\left(\begin{array}{cccccc}
\frac{\partial F_{c n s u}}{\partial u}+\frac{\partial F_{c t s u}}{\partial u} & \frac{\partial F_{c n s u}}{\partial v}+\frac{\partial F_{c t s u}}{\partial v} & 0 & 0 & 0 & 0 \\
\frac{\partial F_{c n s v}}{\partial u}+\frac{\partial F_{c t s v}}{\partial u} & \frac{\partial F_{c n s v}}{\partial v}+\frac{\partial F_{c t s v}}{\partial v} & 0 & 0 & 0 & 0 \\
0 & 0 & 0 & 0 & 0 & 0 \\
0 & 0 & 0 & 0 & 0 & 0 \\
0 & 0 & 0 & 0 & 0 & 0 \\
\frac{\partial T_{c t s}}{\partial u} & \frac{\partial T_{c t s}}{\partial v} & 0 & 0 & 0 & 0
\end{array}\right),
$$

where

$$
\begin{aligned}
\frac{\partial F_{c n s u}}{\partial u} & =-\left(K_{c}^{\prime}(G) G+K_{c}(G)\right) \frac{\partial G}{\partial u} \frac{u}{r}+K_{c}(G) G \frac{1}{r^{2}} \frac{\partial G}{\partial u} u-\frac{K_{c}(G) G}{r}, \\
\frac{\partial F_{c n s u}}{\partial v} & =-\left(K_{c}^{\prime}(G) G+K_{c}(G)\right) \frac{\partial G}{\partial v} \frac{u}{r}+K_{c}(G) G \frac{1}{r^{2}} \frac{\partial G}{\partial v} u, \\
\frac{\partial F_{c n s v}}{\partial u} & =-\left(K_{c}^{\prime}(G) G+K_{c}(G)\right) \frac{\partial G}{\partial u} \frac{v}{r}+K_{c}(G) G \frac{1}{r^{2}} \frac{\partial G}{\partial u} v, \\
\frac{\partial F_{c n s v}}{\partial v} & =-\left(K_{c}^{\prime}(G) G+K_{c}(G)\right) \frac{\partial G}{\partial v} \frac{v}{r}+K_{c}(G) G \frac{1}{r^{2}} \frac{\partial G}{\partial v} v-\frac{K_{c}(G) G}{r},
\end{aligned}
$$




$$
\begin{aligned}
\frac{\partial F_{c t s u}}{\partial u} & =\mu_{s}\left(K_{c}^{\prime}(G) G+K_{c}(G)\right) \frac{\partial G}{\partial u} \frac{v}{r}-\mu_{s} K_{c}(G) G \frac{1}{r^{2}} \frac{\partial G}{\partial u} v \\
\frac{\partial F_{c t s u}}{\partial v} & =\mu_{s}\left(K_{c}^{\prime}(G) G+K_{c}(G)\right) \frac{\partial G}{\partial v} \frac{v}{r}-\mu_{s} K_{c}(G) G \frac{1}{r^{2}} \frac{\partial G}{\partial v} v+\mu_{s} \frac{K_{c}(G) G}{r}, \\
\frac{\partial F_{c t s v}}{\partial u} & =-\mu_{s}\left(K_{c}^{\prime}(G) G+K_{c}(G)\right) \frac{\partial G}{\partial u} \frac{u}{r}+\mu_{s} K_{c}(G) G \frac{1}{r^{2}} \frac{\partial G}{\partial u} u-\mu_{s} \frac{K_{c}(G) G}{r}, \\
\frac{\partial F_{c t s v}}{\partial v} & =-\mu_{s}\left(K_{c}^{\prime}(G) G+K_{c}(G)\right) \frac{\partial G}{\partial v} \frac{u}{r}+\mu_{s} K_{c}(G) G \frac{1}{r^{2}} \frac{\partial G}{\partial v} u, \\
\frac{\partial T_{\mathrm{ftsu}}}{\partial u} & =-\mu_{s}\left(K_{c}^{\prime}(G) G+K_{c}(G)\right) R_{e} \frac{\partial G}{\partial u} \\
\frac{\partial T_{\mathrm{fts} u}}{\partial v} & =-\mu_{s}\left(K_{c}^{\prime}(G) G+K_{c}(G)\right) R_{e} \frac{\partial G}{\partial v}
\end{aligned}
$$

with $K_{c}^{\prime}(G)=\frac{k_{c} \lambda}{1+(\pi \lambda G)^{2}}, \frac{\partial G}{\partial u}=\frac{u}{r}, \frac{\partial G}{\partial v}=\frac{v}{r}$.

- Applying the correction : $\mathbf{D}_{i+1}=\mathbf{D}_{i}+d \mathbf{D}_{i}$.

- If the relative error $\frac{\left\|d \mathbf{D}_{i}\right\|_{2}}{\left\|\mathbf{D}_{i+1}\right\|_{2}}$ is smaller than a criterion $\varepsilon_{0}$, the iterative loop is stopped. Otherwise, the process returns to step 2.

\section{Appendix B. Fourth-order Runge-Kutta with an adaptive time-step algorithm}

Eq. (43) can be solved by applying the RK4 with a constant time step $d t$. Assuming that the system displacement $\mathbf{q}_{n}$ and velocity $\dot{\mathbf{q}}_{n}$ at $t_{n}$ are known, their values at $t_{n+1}=t_{n}+d t$ are computed by determining four slopes:

- Slope 1 :

$$
\mathbf{k}_{11}=d t \dot{\mathbf{q}}_{n}, \quad \mathbf{k}_{12}=d t \mathbf{m}^{-1}\left(\mathbf{f}\left(t_{n}, \boldsymbol{\Phi} \mathbf{q}_{n}, \boldsymbol{\Phi} \dot{\mathbf{q}}_{n}\right)-\mathbf{k} \mathbf{q}_{n}-\mathbf{c} \dot{\mathbf{q}}_{n}\right)
$$

- Slope 2 :

$$
\begin{aligned}
& \mathbf{q}_{i}=\mathbf{q}_{n}+\frac{\mathbf{k}_{11}}{2}, \quad \dot{\mathbf{q}}_{i}=\dot{\mathbf{q}}_{n}+\frac{\mathbf{k}_{12}}{2}, \\
& \mathbf{k}_{21}=d t \dot{\mathbf{q}}_{i}, \quad \mathbf{k}_{22}=d t \mathbf{m}^{-1}\left(\mathbf{f}\left(t_{n}+\frac{d t}{2}, \boldsymbol{\Phi} \mathbf{q}_{i}, \boldsymbol{\Phi} \dot{\mathbf{q}}_{i}\right)-\mathbf{k} \mathbf{q}_{i}-\mathbf{c} \dot{\mathbf{q}}_{i}\right)
\end{aligned}
$$

- Slope 3 :

$$
\begin{aligned}
& \mathbf{q}_{i}=\mathbf{q}_{n}+\frac{\mathbf{k}_{21}}{2}, \quad \dot{\mathbf{q}}_{i}=\dot{\mathbf{q}}_{n}+\frac{\mathbf{k}_{22}}{2}, \\
& \mathbf{k}_{31}=d t \dot{\mathbf{q}}_{i}, \quad \mathbf{k}_{32}=d t \mathbf{m}^{-1}\left(\mathbf{f}\left(t_{n}+\frac{d t}{2}, \boldsymbol{\Phi} \mathbf{q}_{i}, \boldsymbol{\Phi} \dot{\mathbf{q}}_{i}\right)-\mathbf{k} \mathbf{q}_{i}-\mathbf{c} \dot{\mathbf{q}}_{i}\right)
\end{aligned}
$$

- Slope 4 :

$$
\begin{aligned}
& \mathbf{q}_{i}=\mathbf{q}_{n}+\mathbf{k}_{31}, \quad \dot{\mathbf{q}}_{i}=\dot{\mathbf{q}}_{n}+\mathbf{k}_{32}, \\
& \mathbf{k}_{31}=d t \dot{\mathbf{q}}_{i}, \quad \mathbf{k}_{32}=d t \mathbf{m}^{-1}\left(\mathbf{f}\left(t_{n}+d t, \boldsymbol{\Phi} \mathbf{q}_{i}, \boldsymbol{\Phi} \dot{\mathbf{q}}_{i}\right)-\mathbf{k} \mathbf{q}_{i}-\mathbf{c} \dot{\mathbf{q}}_{i}\right)
\end{aligned}
$$


- Computing the system displacement and velocity at $t_{n+1}$

$$
\begin{aligned}
& \mathbf{q}_{n+1}=\mathbf{q}_{n}+\frac{\mathbf{k}_{11}+\mathbf{k}_{41}}{6}+\frac{\mathbf{k}_{21}+\mathbf{k}_{31}}{3}, \\
& \dot{\mathbf{q}}_{n+1}=\dot{\mathbf{q}}_{n}+\frac{\mathbf{k}_{12}+\mathbf{k}_{42}}{6}+\frac{\mathbf{k}_{22}+\mathbf{k}_{32}}{3},
\end{aligned}
$$

The nonlinear dynamic computation may require a small time step to avoid the numerical problems and then induce a large computational time. The following adaptive time-step algorithm is applied to reduce the computation time.

- Assuming that the system displacement $\mathbf{q}_{n}$ and velocity $\dot{\mathbf{q}}_{n}$ at $t_{n}$ are known,

- Computing $\mathbf{q}_{n+1}^{(1)}, \dot{\mathbf{q}}_{n+1}^{(1)}$ with a time step $d t$ and $\mathbf{q}_{n+1}^{(2)}, \dot{\mathbf{q}}_{n+1}^{(2)}$ by two consecutive time steps $d t / 2$

- Estimating the numerical error: $e r=\left(\left\|\mathbf{q}_{n+1}^{(1)}-\mathbf{q}_{n+1}^{(2)}\right\|_{2}+\left\|\dot{\mathbf{q}}_{n+1}^{(2)}-\dot{\mathbf{q}}_{n+1}^{(2)}\right\|_{2}\right) / 15$.

- If $e r \leq \varepsilon_{0} / 100$ with $\varepsilon_{0}$ the threshold criterion, then $d t_{\text {new }}=\beta d t_{\text {old }}, \mathbf{q}_{n+1}=\mathbf{q}_{n+1}^{(2)}, \dot{\mathbf{q}}_{n+1}=\dot{\mathbf{q}}_{n+1}^{(2)}$ and the next time iteration with time step $d t_{\text {new }}$ is processed.

Otherwise,

- If $\varepsilon_{0} / 100<e r \leq \varepsilon_{0}$, then $\mathbf{q}_{n+1}=\mathbf{q}_{n+1}^{(2)}, \dot{\mathbf{q}}_{n+1}=\dot{\mathbf{q}}_{n+1}^{(2)}$ the next time iteration is processed with the same time step

- If not, $d t_{\text {new }}=d t_{\text {old }} / \alpha$ then return to the second step

with $\alpha, \beta$ two coefficients given by the user. In this work, $\alpha$ and $\beta$ are set to 1.1 and 1.01 respectively.

\section{References}

[1] P. D. Spanos, A. M. Chevallier, N. P. Politis, M. L. Payne, Oil well drilling: A vibrations perspective, The Shock and Vibration Digest 35 (2003) 81-99.

[2] H. Melakhessou, A. Berlioz, G. Ferraris, A nonlinear well-drillstring interaction model, Journal of vibration and acoustics-Transactions of the ASME 125 (2003) 46-52.

[3] V. Dunayevsky, F. Abbassian, A. Judzis, Dynamic stability of drillstrings under fluctuating weight on bit, SPE Drilling and Completion 8 (1993) 84-92.

[4] H. Qiu, J. Yang, S. Butt, Investigation on bit stick-slip vibration with random friction coefficients, Journal of Petroleum Science and Engineering 164 (2018) 127-139.

[5] K. MacDonald, Failure analysis of drillstring and bottom hole assembly components, Engineering Failure Analysis 1 (1994) 91-117.

[6] S. Molaei, M. Attarian, M. Kermajani, S. Jahromi, M. Alemi, Failure analysis of a damaged drilling stabilizer, Engineering Failure Analysis 103 (2019) 517-529.

[7] J. Šporin, P. Mrvar, M. Petrič, G. Vižintin, Z. Vukelić, The characterization of wear in roller cone drill bit by rock material - sandstone, Journal of Petroleum Science and Engineering 173 (2019) 1355-1367.

[8] D. Dareing, B. Livesay, Longitudinal and angular drill-string vibrations with damping, Journal of Engineering for Industry, Transactions of the ASME 90 (1968) 671-679. 
[9] J. Bailey, I. Finnie, An analytical study of drillstring vibration, Journal of Engineering for Industry, Transactions of the ASME 82 (1960) $122-128$

[10] Y.-Q. Lin, Y.-H. Wang, Stick-slip vibration of drill strings, Journal of Engineering for Industry-Transactions of the ASME 113 (2019) $38-43$.

[11] Y. Liu, W. Lin, J. P. Chávez, R. De Sa, Torsional stick-slip vibrations and multistability in drill-strings, Applied Mathematical Modelling 76 (2019) 545-557.

[12] J. Brett, The genesis of torsional drillstring vibrations, SPE Drilling Engineering 7 (1992) 168-174.

[13] M. Vaz, M. Patel, Analysis of drill strings in vertical and deviated holes using the Galerkin method, Engineering Structures 17 (1995) $437-442$.

[14] R. Dufour, A. Berlioz, Parametric instability of a beam due to axial excitations and to boundary conditions, Journal of vibration and acoustics-Transactions of the ASME 120 (1998) 461-467.

[15] A. Berlioz, J. D. Hagopian, R. Dufour, E. Draoui, Dynamic behavior of a drill-string: Experimental investigation of lateral instabilities, Journal of vibration and acoustics-Transactions of the ASME 118 (1996) 292-298.

[16] K.-L. Nguyen, Q.-T. Tran, M.-A. Andrianoely, L. Manin, R. Dufour, S. Menand, M. Mahjoub, Campbell diagram computation for a drillstring immersed in curved wells, Journal of vibration and acoustics-Transactions of the ASME 141 (2019) 041009.

[17] A. P. Christoufou, A. S. Yigit, Dynamic modelling of rotating drillstrings with borehole interactions, Journal of Sound and Vibration 206 (1997) 243-260.

[18] T. G. Ritto, C. Soize, R. Sampaio, Non-linear dynamics of a drill-string with uncertain model of the bit-rock interaction, International Journal of Non-Linear Mechanics 44 (2009) 865-876.

[19] Q.-T. Tran, K.-L. Nguyen, L. Manin, M.-A. Andrianoely, R. Dufour, M. Mahjoub, S. Menand, Nonlinear dynamics of directional drilling with fluid and borehole interactions, Journal of Sound and Vibration (2019). doi:https://doi.org/10.1016/j.jsv.2019.114924.

[20] X. Liu, N. Vlajic, X. Long, G. Meng, B. Balachandran, Coupled axial-torsional dynamics in rotary drilling with state-dependent delay: stability and control, Nonlinear Dyn 78 (2014) 1891-1906.

[21] S. K. Gupta, P. Wahi, Global axial-torsional dynamics during rotary drilling, Journal of Sound and Vibration 375 (2016) $332-352$.

[22] K. Nandakumar, M. Wiercigroch, Stability analysis of a state dependent delayed, coupled two dof model of drill-string vibration, Journal of Sound and Vibration 332 (2013) 2575-2592.

[23] Y. Yan, M. Wiercigroch, Dynamics of rotary drilling with non-uniformly distributed blades, International Journal of Mechanical Sciences 160 (2019) 270-281.

[24] E. Kreuzer, H. Struck, Mechanical modelling of drill-strings, Proc. Appl. Math. Mech. 3 (2003) 88-91.

[25] C.-M. Liao, B. Balachandran, M. Karkoub, Y. Abdel-Magid, Drill-string dynamics: Reduced-order models and experimental studies, Journal of vibration and acoustics-Transactions of the ASME 133 (2011) 041008.

[26] A. Cunha Jr, C. Soize, R. Sampaio, Computational modeling of the nonlinear stochastic dynamics of horizontal drillstrings, Computational Mechanics 56 (2015) 849-878.

[27] J. K. Wilson, G. Heisig, Nonlinear drillstring-dynamics modeling of induced vibrations in unconventional horizontals, SPE Drilling and Completions 30 (2015) 243-256.

[28] T. Feng, I. Kim, D. Chen, Dynamic modeling of directional drillstring: A linearized model considering well profile, Journal of Dynamic Systems, Measurement, and Control 140 (2018) 061005.

[29] T. Feng, S. Bakshi, Q. Gu, D. Chen, A finite element modeling framework for curved beam dynamics considering nonlinearities and contacts, Journal of Computational and Nonlinear Dynamics 14 (2019) 081003.

[30] W. C. Hurty, Dynamic analysis of structural systems using component modes, AIAA Journal 3 (1965) 678-685.

[31] W. A. Benfield, R. F. Hruda, Vibration analysis of structures by component mode substitution, AIAA Journal 9 (1971) $1255-1261$.

[32] R. M. Hintz, Analytical methods in component modal synthesis, AIAA Journal 13 (1975) 1007-1016.

[33] C. Joannin, B. Chouvion, F. Thouverez, J.-P. Ousty, M. Mbaye, A nonlinear component mode synthesis method for the computation of steady-state vibrations in non-conservative systems, Mechanical Systems and Signal Processing 83 (2017) 75-92. 
[34] M. C. C. Bampton, R. R. Craig Jr., Coupling of substructures for dynamic analyses, AIAA Journal 6 (1968) $1313-1319$.

[35] R. J. Fritz, The effects of an annular fluid on the vibration of a long rotor, part 1 - theory, Journal of Basic Engineering, ASME 92 (1970) 923-929.

[36] S. S. Chen, Fluid damping for circular cylindrical structures, Nuclear Engineering and Design 63 (1981) 81-100.

[37] F. Axisa, J. Antunes, Flexural vibrations of rotors immersed in dense fluids. Part I: Theory, Journal of Fluids and Structures 6 (1992) 3-21.

[38] J. Antunes, F. Axisa, F. Hareux, Flexural vibrations of rotors immersed in dense fluids. Part II: Experiments, Journal of Fluids and Structures 6 (1992) 23-38.

[39] T.-N. Le, J.-M. Battini, M. Hjiaj, Dynamics of 3D beam elements in a corotational context: A comparative study of established and new formulations, Finite Elements in Analysis and Design 61 (2012) 97-111. 